\title{
Barrier mechanisms in the developing brain
}

\author{
Norman R. Saunders*, Shane A. Liddelow and Katarzyna M. Dziegielewska
}

Department of Pharmacology, The University of Melbourne, Parkville, VIC, Australia

Edited by:

Joana A. Palha, University of Minho,

Portugal

Reviewed by:

Jason B. Wu, Cedars-Sinai Medical Center, USA

Adam Chodobski, Brown University, USA

\section{${ }^{*}$ Correspondence:}

Norman R. Saunders, Department of

Pharmacology, University of

Melbourne, Parkville, VIC 3010,

Australia.

e-mail:n.saunders@unimelb.edu.au
The adult brain functions within a well-controlled stable environment, the properties of which are determined by cellular exchange mechanisms superimposed on the diffusion restraint provided by tight junctions at interfaces between blood, brain and cerebrospinal fluid (CSF). These interfaces are referred to as "the" blood-brain barrier. It is widely believed that in embryos and newborns, this barrier is immature or "leaky," rendering the developing brain more vulnerable to drugs or toxins entering the fetal circulation from the mother. New evidence shows that many adult mechanisms, including functionally effective tight junctions are present in embryonic brain and some transporters are more active during development than in the adult. Additionally, some mechanisms present in embryos are not present in adults, e.g., specific transport of plasma proteins across the blood-CSF barrier and embryo-specific intercellular junctions between neuroependymal cells lining the ventricles. However developing cerebral vessels appear to be more fragile than in the adult. Together these properties may render developing brains more vulnerable to drugs, toxins, and pathological conditions, contributing to cerebral damage and later neurological disorders. In addition, after birth loss of protection by efflux transporters in placenta may also render the neonatal brain more vulnerable than in the fetus.

Keywords: blood-brain barrier, blood-CSF barrier, epithelial cell transport, endothelial cell transport, cerebrospinal fluid, fetus, newborn

\section{INTRODUCTION}

Understanding the role of blood-brain barrier mechanisms in normal brain development and possible deleterious effects should these mechanisms be dysfunctional is important from the clinical perspective of whether or not drugs or toxins, once they cross the placenta, may have access to the vulnerable developing brain. A reason given by regulatory bodies in US and European Union for caution in giving drugs to pregnant women or infants is "immaturity" of the blood-brain barrier ${ }^{1,2}$.

One historical reason for belief in barrier immaturity comes from teleological thinking that fetal brains would not need a barrier, because the fetus is protected by a placenta (Barcroft, 1938). The developing brain is necessarily immature compared to that of the adult, but the real question should be about the functional status of the blood-brain barrier mechanisms in embryos, fetuses, and infants, compared to adults.

There is a widespread belief amongst pediatricians, neurologists, neuroscientists, and neurotoxicologists that "the" bloodbrain barrier in the embryo, fetus, and newborn is "immature" implying that it is poorly formed, leaky, or even absent. Statements about the immaturity of the blood-brain barrier frequently seem to be made without evidence, or by reference to an earlier review that also lacks any evidence (e.g., Järup, 2003; Costa et al., 2004; Watson et al., 2006). This seems to be particularly common in the neurotoxicology literature and in toxicology reports (see review by Ek et al., 2012).

Abbreviations: BCRP, breast cancer resistance protein; CSF, cerebrospinal fluid.

${ }^{1}$ http://www.atsdr.cdc.gov/csem/pediatric/docs/pediatric.pdf

${ }^{2}$ www.emea.europa.eu

\section{FUNCTIONAL SIGNIFICANCE OF EARLY DEVELOPMENT OF BRAIN BARRIERS}

Without the diffusion restraint provided by intercellular junctions in brain barrier interfaces it would not be possible to establish efflux or influx mechanisms such as those controlling ionic gradients between blood and cerebrospinal fluid (CSF; Bito and Myers, 1970; Bradbury et al., 1972; Amtorp and Sørensen, 1974; and see Saunders, 1992 for review). In effect, these junctions convert the transport properties of individual cerebral endothelial and choroid plexus epithelial cells into those of the whole interfaces separating blood from brain. Thus transfer from blood to brain and CSF occurs across these interfaces and is known to be present from early stages of brain development for a wide range of metabolically important molecules: glucose (Dermietzel et al., 1992; Vannucci, 1994; Vannucci et al., 1994; Bauer et al., 1995), amino acids (Braun et al., 1980; Cornford et al., 1982; Pardridge and Mietus, 1982; Lefauconnier and Trouvé, 1983), and hormones (Hagenbuch, 2007). The molecular structure of tight junctions of the blood-brain barrier proper in the adult brain has been extensively studied and reviewed (e.g., Abbott et al., 2010).

Figure 1 illustrates the brain of an E16 rat brain immunostained with antibodies to total plasma protein. There is no evidence for any proteins escaping the vasculature, demonstrating functional effectiveness of the blood-brain barrier even so early in development. At this stage of rat development in the brain there are very few blood vessels and the cortex only becomes well vascularized after birth. In contrast, choroid plexuses are already a significant size (Figure 1C) and grow rapidly during the remainder of gestation. It appears that in early stages of brain development the 

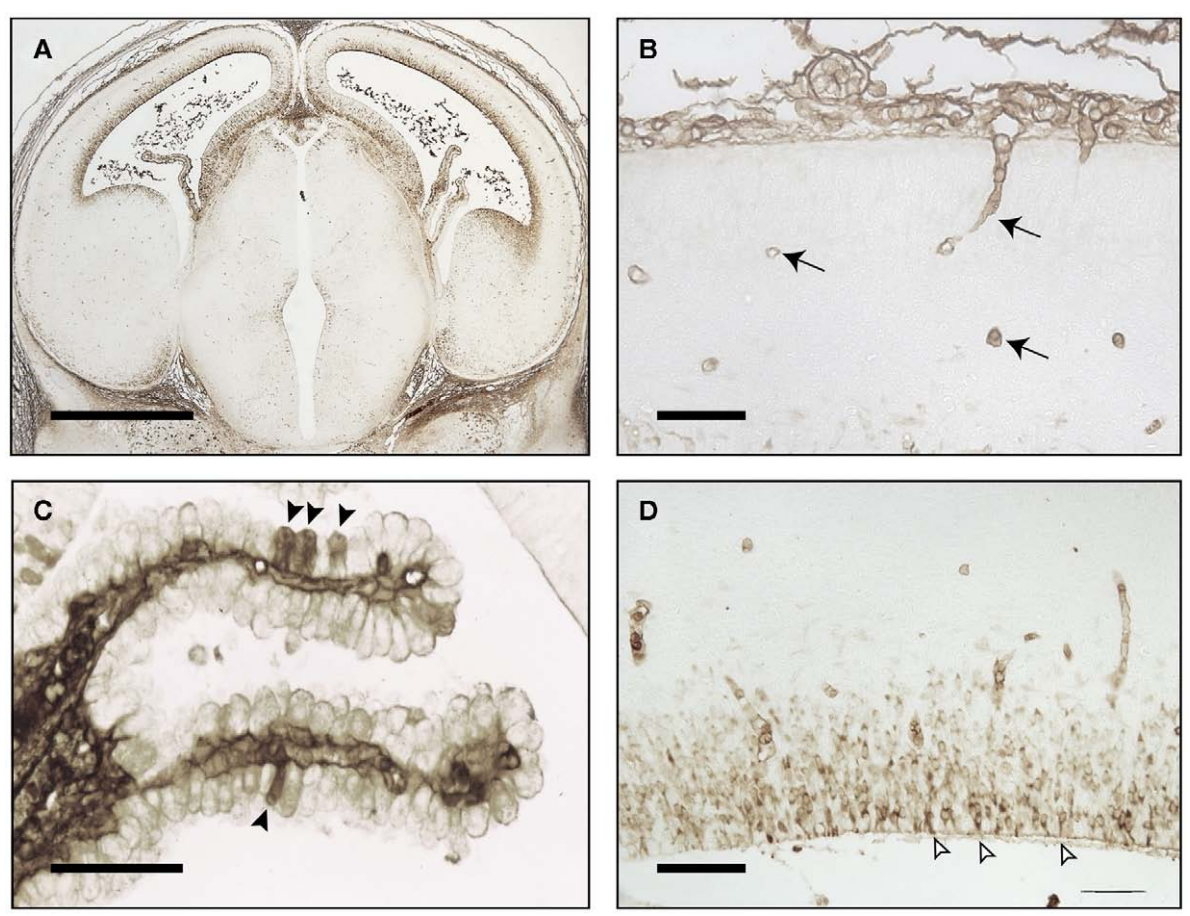

FIGURE 1 | Embryonic day E16 rat brain stained for endogenous plasma proteins. (A) Low power coronal section. Immunostaining in CSF, choroid plexus, and ventricular zone, also few blood vessels in cortex. (B) Higher power of cortex: immunostaining in mesenchymal tissue outside brain surface and blood vessels (arrows), not in brain parenchyma. (C) Choroid plexus: immunostaining in some epithelial cells (arrowheads) and stroma. (D) Immunostaining in neuroependymal cells and blood vessels, not in brain parenchyma outside neuroependyma. Open arrows: sites of strap junctions. Images reproduced from Saunders and Habgood (2011). Scale bars: (A), $100 \mu \mathrm{m}$; (B,D), $25 \mu \mathrm{m}$; (C), $50 \mu \mathrm{m}$. choroid plexuses are the main portals of molecular transfer from blood into brain (Johansson et al., 2008; Liddelow et al., 2009).

Thus far from being incomplete or "leaky," barriers in developing brain are adapted to fetal environments. However, it is important to distinguish functional effectiveness of early tight junctions at the blood-brain barrier from the evidence for their continued molecular and structural organization. This may relate to increased hydrostatic pressure that occurs during fetal development as systemic blood pressure rises in parallel with plasma protein concentration that provides the "colloid" osmotic pressure important for fluid exchange across capillaries.

\section{EARLY STUDIES OF THE BLOOD-BRAIN BARRIER IN THE DEVELOPING BRAIN DYE EXPERIMENTS}

Ehrlich (1885) and Goldmann (1909) showed that parenteral injections of trypan blue and other acidic dyes resulted in staining of almost all tissues except the brain. Biedl and Kraus (1898) and Lewandowsky (1900) found that even the much smaller molecules: bile and sodium ferrocyanide (demonstrated with Prussian blue reaction) only had toxic effects when injected directly into the brain. It was these early experiments that led to the concept of the brain being protected by a mechanism called the blood-brain barrier, a term that appears to have been first used by Lewandowsky (1900). These experiments were soon followed by similar ones using embryos or newborns of various species. Most of the early reports of experiments using trypan blue gave the same result as in adults, i.e., most of the brain was not stained apart from the circumventricular organs (Wislocki, 1920, guinea pig embryo; Stern and Peyrot, 1927; Stern and Rapoport, 1928; Stern et al., 1929, newborn rats, rabbits, and guinea pigs). Stern et al. (1929) stressed the importance of not injecting too much dye. This may explain one of the few early reports of brain staining following dye injection by Penta (1932) because he used multiple and such large injections that most of his experimental animals (newborn rabbits) died from the toxic effects of the dye (see Saunders, 1992). Behnsen (1927) is perhaps the most frequently cited paper supposedly showing staining of the brain following dye injections in postnatal mice. However, his paper did not actually show this but instead his results illustrated that the sites of dye entry in the adult animals corresponded precisely to sites of maximal accumulation in the young mice. Rather curiously Behnsen (1927) chose to illustrate his findings with drawings of sagittal sections using adult mouse brain for both adult and postnatal (2-3 week old) animals. Since areas of the brain such as the cerebral cortex are not yet fully developed at 2-3 weeks of age, the distribution of dye at this age would have appeared more widespread than in the adult, without actually being so. In the brain region with the least mature blood vessels (cerebral cortex) there was no dye staining of the brains of the younger mice. A key often overlooked reference in the field is the one in which both rabbit and human fetal material was studied using trypan blue injections (Gröntoft, 1954). The study showed 
clearly that in human fetuses (5-26 cm long) obtained from legal abortions, providing the dye was injected within $10 \mathrm{~min}$ following placental separation, the brains remained dye-free indicating that the blood-brain barrier was impermeable to the dye; at later times or in aborted embryos that could not be examined until some time after delivery, the brains stained blue following dye injection. Gröntoft (1954) considered this to be due to an effect of asphyxia on the blood-brain barrier following the death of the fetuses. He confirmed this under controlled experimental conditions in rabbit fetuses in which he was able to study the brains at predetermined times after injection and death of the fetuses.

\section{SODIUM FERROCYANIDE}

Sodium ferrocyanide is a small molecular weight compound ( $\mathrm{mol}$ wt 204) about the same size as sucrose (342 Da; molecular radius $5.1 \AA$ ). When treated with acid it gives a blue color (Prussian blue reaction). In what was probably the first brain barrier experiment in an embryo, Weed (1917) injected sodium ferrocyanide into the neural tube of pig embryos (19 mm, E20; term is 114 days) and showed that the blue staining following treatment with slightly acidic solutions of iron salts (Prussian blue reaction) was confined to the neural tube and did not penetrate out into rest of the embryo. This paper seems to have been overlooked by the bloodbrain barrier field, perhaps because it is the converse of a classical barrier experiment in which the marker was injected parenterally (cf. Stern and Peyrot, 1927; Stern and Rapoport, 1928; Stern et al., 1929).

In spite of the above studies clearly showing lack of penetration of small molecular compounds even into an embryonic brain, there are nevertheless numerous reports claiming an absence or immaturity of the blood-brain barrier in the fetus and neonate continue to be published (see Ek et al., 2012 for review).

There are several well-known fetal-specific mechanisms that are different from the adult that reflect adaptation to a fetal-specific environment (e.g., fetal hemoglobin, Palis et al., 2010). Similarly, during development, brain barriers demonstrate some important differences, particularly in transport mechanisms, many of which have only recently begun to be described. These differences probably reflect mechanisms important for brain development rather than deficiencies compared to adult brain. This review will summarize the main brain barrier mechanisms in the adult and during development. In the last part of the review we shall consider evidence that blood-brain barrier mechanisms, while functionally effective in the developing brain, may nonetheless be more susceptible than in the adult to adverse circumstances and that damage to brain barrier mechanisms during development may lead to neurological and neuropsychological dysfunction in later life.

\section{BRAIN BARRIERS}

The main interfaces across which exchange occurs between the blood and the internal environment of the brain (brain interstitial fluid and CSF) are illustrated in Figure 2. There are five main barrier interfaces involved: (i) the blood-brain barrier proper at the level of the endothelium of the cerebral blood vessels; (ii) the arachnoid barrier between the CSF in the subarachnoid space and the dura; (iii) the pia/glia limitans between the CSF and extracellular fluid of the brain, which is much more complex in the embryo; (iv) the CSF-brain barrier, which is only a significant barrier in the embryo, created by separation of the ventricular system from the extracellular fluid of the brain by strap junctions in the neuroependyma; and (v) the blood-CSF barrier at the level of the choroid plexus epithelial cells (Figure 2).

\section{CELLULAR CONSTITUENTS OF BARRIER INTERFACES IN THE DEVELOPING BRAIN}

The principal morphological basis of these barriers lies in intercellular junctions that provide a diffusional restraint between compartments.

\section{The neurovascular unit}

The term blood-brain barrier has a long history, but it has become increasingly recognized that it does not adequately encompass the wide range of morphological features and functional characteristics that it is now known to involve. For this reason the term "neurovascular unit" (Neuwelt, 2004) is being increasingly used. It comprises the endothelial cells, pericytes, microglia, astrocytes, and basement membrane that are characteristic of the cerebral vasculature. The term refers more to the close anatomical and functional association of these different cell types without implying any specific mechanisms.

\section{Endothelial cells}

Two features characterize the cerebral endothelial cells that constitute the blood-brain barrier. These are circumferential tight junctions, which occlude the intercellular space between adjacent endothelial cells and a lack of pinocytotic vesicles in the cytoplasm (Brightman and Reese, 1969). There are several reports that there are many more vesicles in the endothelial cells of developing brain vasculature (Donahue and Pappas, 1961; Dziegielewska et al., 1979) with a decline as development proceeds. In contrast Stewart and Hayakawa $(1987,1994)$ reported that vesicles were virtually absent in early cerebral blood vessels. This discrepancy could perhaps be due to differences in fixation or to different classes of blood vessels being examined. Dziegielewska et al. (1979) also reported that following intravenous Alcian blue injection in fetal sheep, the dye (which is electron-dense and binds to plasma albumin) could be seen within numerous vesicles and tubules in the cytoplasm of the endothelial cells; dye was also present in the basement membrane, but not inside tight junctions. However, this aspect of brain barrier development has otherwise been little studied. In contrast the question of whether cerebral interendothelial tight junctions in early brain development are as impermeable to markers such as dyes or horseradish peroxidase has attracted a lot of attention, with conflicting results being reported over many years. Thus some early studies using transmission electron microscopy and/or freeze fracture, showed well-formed tight junctions between cerebral endothelial cells from early in vascularization of the brain (Møllgård and Saunders, 1975; Møllgård et al., 1979; Bass et al., 1992; Bauer et al., 1993). Some studies claimed that cerebral endothelial tight junctions in fetal mouse and rat brain showed ultrastructural features such as the proportion of the junction composed of zonulae occludens which increased, while junctional clefts decreased, and expanded junctional clefts virtually disappeared (Stewart and Hayakawa, 1987, 1994). In a freeze fracture study, 


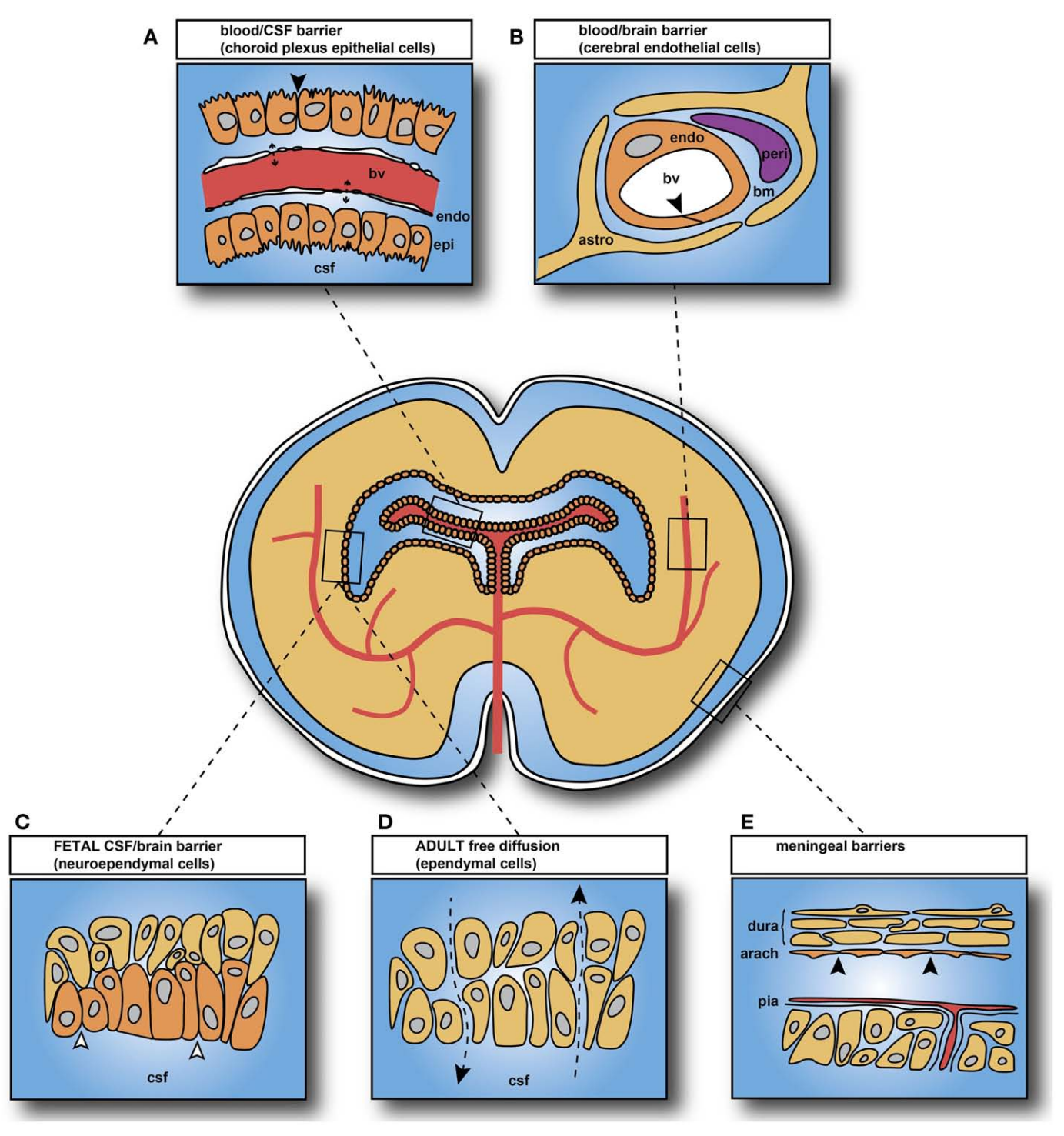

FIGURE 2 | Brain barrier interfaces. (A) Blood-cerebrospinal fluid (CSF) barrier: tight junctions between choroid plexus epithelial cells. (B) Blood-brain barrier: tight junctions between endothelial cells. (C) CSF-brain barrier only present in embryos and fetuses: strap junctions between neuroependymal cells. (D) CSF-brain interface in adult: gap junctions between ependymal cells, with free diffusion pathway (Arrowheads and broken lines). (E) Arachnoid barrier. In adult: tight junctions between cells of the inner layer of the arachnoid membrane and between endothelial cells of pial blood vessels. In embryos: additional membrane specializations at the CSF-pial interface (Møllgård et al., 1987). Abbreviations: bv, blood vessel; endo, endothelial cell; epi, epithelial cell; bm, basement membrane; peri, pericyte; astro, astrocyte (astrocytes not yet differentiated in brain when blood vessels first appear; thus they cannot contribute to tight junction formation in early brain development). Black arrowheads: sites of tight junctions; open arrowheads: sites of strap junctions. Redrawn from Saunders et al. (2008).
Kniesel et al. (1996) identified changes in strand pattern during cerebral vascular development, which they suggested correlated with greater permeability and subsequent developmental decline in blood-brain barrier permeability. Stewart and Hayakawa (1987) assessed blood-brain barrier permeability by measuring peroxidase activity in homogenized brain at different ages. However, the choroid plexuses are disproportionately larger in the developing brain (Johansson et al., 2008) and transfer proteins across their epithelial cells (see below). It is unclear whether choroid plexus was removed from the brain samples and the possibility that HRP may have entered the brain via the plexuses was not considered. Kniesel et al. (1996) did not include any permeability studies in parallel with their ultrastructural observations, but relied on comparisons with in vitro cultures of cerebral endothelial cells to support their conclusion that changes in freeze fracture replicas with age correlated with supposed greater blood-brain barrier permeability in the developing brain.

Later studies (Nitta et al., 2003; Ek et al., 2006) appear to confirm the earlier findings of well-formed tight junctions in the early stages of vascularization of the brain. The advent of small molecular sized water-soluble probes that can be visualized at the electron microscopical level has shown that these junctions are 
indeed functionally tight to small molecules (Ek et al., 2006). Thus in these more recent light microscopical and ultrastructural studies using amounts of tracer that only increased circulating blood volume and protein concentration to a limited extent $(<10 \%)$ the tight junctions of endothelial cells in cerebral blood vessels and in embryos and neonates were found to restrict the passage of low molecular weight molecules (Ek et al., 2006; Johansson et al., 2006; Daneman et al., 2010a). In contrast, some earlier studies in the developing brain claimed leakiness of cerebral blood vessels, but used large injection volumes or concentrations of the tracer horseradish peroxidase (e.g., Wakai and Hirokawa, 1978a,b; Risau et al., 1986; Risau and Wolburg, 1990; see Saunders, 1992 for review). The more recent findings of Ek et al. (2006), Johansson et al. (2006), and Daneman et al. (2010a) show that the physical basis for the brain barrier mechanism is already present and functionally effective from very early in development.

Immunolocalization of tight junctional proteins, such as claudin 5 and occludin, shows that these are present in brain barrier interfaces soon after blood vessels invade the brain in mammals (Ek et al., 2006; Daneman et al., 2010a) including humans (Virgintino et al., 2004). Many of the molecular studies of tight junction proteins have been carried out using in vitro preparations, often of cultures of artificial cell lines such as Madin-Darby bovine kidney (MDBK) cells and human intestinal epithelial cells (T84; Furuse et al., 1994, 2001; Itoh et al., 2001) mouse embryonic feeder cells (Saitou et al., 1998) MDCK cells (Sonoda et al., 1999; Colegio et al., 2003; Blasig et al., 2006). These studies have provided valuable insights into the molecular structure of tight junctions, which could then be followed up in material from normal brain endothelia and epithelia in vitro (Hirase et al., 1997; Haseloff et al., 2005; Cohen-Kashi Malina et al., 2009) and in vivo (Nitta et al., 2003; Furuse and Tsukita, 2006; Sadowska et al., 2009; Xie et al., 2010). However, when used to assess barrier interface permeability in vitro this has usually been done indirectly by measuring transepithelial or transendothelial resistance (TEER), which is assumed to equate to a low resistance pathway via tight junctions (Frömter and Diamond, 1972). It is not clear how well these in vitro systems reflect the situation in vivo, but it is becoming increasingly clear that they may not always do so, resulting in a number of misleading conclusions. As pointed out by Armulik et al. (2011), it was considered for some years on the basis of in vitro studies that pericytes played an important role in development and maintenance of cerebral interendothelial cell tight junctions; however two studies of transgenic mice with deficient pericytes showed that in these animals an increase in vascular permeability correlated with increased endothelial transcytosis rather than tight junction permeability (Armulik et al., 2010; Daneman et al., 2010b) as is discussed in the next section.

\section{Pericytes}

Daneman et al. (2010b) compared mice with null and hypomorphic alleles of Pdgfrb (platelet-derived growth factor receptor- $\beta$ ) which have defects in pericyte generation. They showed that pericytes are necessary for formation of a functionally effective blood-brain barrier and that pericyte coverage of blood vessels determines relative vascular permeability. Pericytes were found to regulate functional formation of tight junctions and vesicle trafficking in CNS endothelial cells, however, they did not induce blood-brain barrier specific gene expression in cerebral endothelial cells; rather they inhibited the expression of molecules that increase vascular permeability and infiltration of immune cells. These effects on blood-brain barrier formation occurred a week before the differentiation of astrocytes, the cells that many have suggested are responsible for induction of tight junctions during blood-brain barrier formation (see next section).

\section{Astrocytes}

In the adult brain astrocytic end feet encircle almost the entire circumference of endothelial cells of cerebral capillaries (Caley and Maxwell, 1970; Xu and Ling, 1994). They are an important component of the neurovascular unit and are thought to make significant contributions to blood-brain barrier functions (Abbott et al., 2006). Their role in the developing brain has been more controversial. When in vitro blood-brain barrier models were first being developed it was found that the presence of either cultured astrocytes or conditioned medium from cultured astrocytes produced cells with more complex tight junctions (Tao-Cheng et al., 1987) and this was essential for the preparation of cerebral endothelial monolayers with high transendothelial resistance (Dehouck et al., 1990; Rubin et al., 1991). A study that has been particularly influential in discussion of the possible role of astrocytes in development of blood-brain barrier properties in the immature brain was that of Janzer and Raff (1987). These authors cultured cerebral endothelial cells in the anterior chamber of the eye and reported that only in the presence of astrocytes were blood vessels formed that retained dye within their lumena. They compared astrocyte implants with fibroblast implants and found that the vessels associated with the fibroblast grafts were "leaky" to Evans blue. Janzer and Raff (1987) interpreted their results as evidence that blood vessels with impermeable tight junctions were formed in the presence of astrocytes. However, this was not confirmed by electron microscopy; without ultrastructural evidence a claim of tight junction formation was unwarranted. The study was repeated by Holash et al. (1993) who did include electronmicroscopical observations. They found that astrocytes implanted into the anterior chamber formed grafts that were poorly vascularized and when examined by electron microscopy the iridial blood vessels associated with the astrocyte grafts did not change their ultrastructural characteristics to those of brain capillaries. In addition, grafted fibroblasts formed invasive masses that were well vascularized with fenestrated (non-barrier) blood vessels. Holash et al. (1993) suggested that it was the contrast in dye penetration into these well vascularized fibroblast grafts compared to the poorly vascularized astrocyte grafts that led to the incorrect conclusion of barrier formation in vessels penetrating the astrocyte grafts. However, this study is rarely cited in contrast to the paper of Janzer and Raff (1987), a depressing reflection that even scientists will cite the evidence that supports their preconceived ideas, not to mention the undue influence of some journals in which a particular study is published. A limitation of studies of blood-brain barrier interfaces in vitro is that the endothelial cells used were generally from adult brains and would therefore already have their adult properties; however it may be that their role is in maintenance of tight junctions rather than in their initial formation. 
What seems to have been overlooked by the proponents of the idea that astrocytes are essential for tight junction formation in the blood vessels of the developing brain is that there are no astrocytes present in the developing brain when it is first vascularized (Caley and Maxwell, 1970; Daneman et al., 2010a). As first shown by Stewart and Wiley (1981) using chick-quail chimeras, tight junction formation in cerebral vessels is induced by some factor in the neural tissue of the developing brain. The vessels are tight to proteins and small molecules from as early as vessels first grow into the neural tissue (Bauer et al., 1993; Ek et al., 2006). It is not yet clear what the induction factor(s) is/are. However, as indicated above it seems that the pericytes make an important contribution to tight junction formation (Daneman et al., 2010b). The main period of differentiation of astrocytes and the encirclement of capillaries occur in rodents in the first 3 weeks of postnatal life; this is also the main period of vascularization of the developing brain in rodents (Caley and Maxwell, 1970). Thus it is possible that astrocytes contribute to tight junction-induction during this period of intense vascularization.

\section{Basement membrane}

The basement membrane surrounds all cerebral capillaries and is an important component of the neurovascular unit. Bär and Wolff (1972) have given a detailed ultrastructural description of formation of the basement membrane around capillaries from E14 in rat cerebral cortex. The basement membrane is thought to be formed by secretion of constituents by cerebral endothelial cells and by pericytes (Stratman and Davis, 2011) embedded in this structure (Figure 1B). There is also evidence that astrocytes contribute at later stages in vascularization of the brain (del Zoppo and Milner, 2006). The main constituents of the basement membrane are type IV collagen from endothelial cells and type I collagen from pericytes as well as fibronectin, thrombospondin (Canfield et al., 1989), and agrin (Barber and Lieth, 1997). In the developing brain basement membrane is apparent at least as early as E20 in rat fetuses and becomes denser and wider in the postnatal brain (Donahue and Pappas, 1961). In human fetuses it has been identified in cerebral capillaries at least as early as 8 weeks gestation in a detailed immunohistochemical study of the distribution of laminin $\beta 1$ and laminin $\beta 2$ chains (Roediger et al., 2010).

\section{Wnt/BCATENIN PATHWAY IN BLOOD-BRAIN BARRIER DEVELOPMENT}

A major contribution to understanding the early stages of bloodbrain barrier mechanism development was the publication of three papers implicating the $\mathrm{Wnt} / \beta$ catenin pathway in some important features of blood-brain barrier function (Liebner et al., 2008; Stenman et al., 2008; Daneman et al., 2009). Wnt is an acronym for wingless (wg) first identified in Drosophila and INT-1, first identified in virally induced mammary tumors in mice. They are the two founding member genes of the Wnt signaling pathway. Thus far three major pathways downstream from Wnt have been identified. Of these the $\mathrm{Wnt} / \beta$-catenin pathway seems to be important for aspects of angiogenesis and blood-brain barrier development. The Wnt/ßcatenin pathway is also referred to as the canonical Wnt signaling pathway (canonical: "Of the nature of a general rule or standard formula" Oxford English Dictionary). Signaling via Wnt involves a complex molecular mechanism the end result of which is blocking of intracellular mechanisms that would normally result in ubiquitination and proteasome-dependent degradation (Rudloff et al., 2011). Several studies have shown that interference with the $\mathrm{Wnt} / \beta$-catenin pathway results in reduced vessel numbers, loss of capillary beds, and formation of hemorrhagic vascular malformations; in addition $\mathrm{Wnt} / \beta$-catenin signaling has also been shown to regulate the expression of the blood-brain barrier-specific glucose transporter glut-1 (Stenman et al., 2008; Daneman et al., 2009). In a study using different transgenic mice at postnatal ages and primary cultures of mouse brain endothelial cells (the age of the animals from which these were derived was not specified) Liebner et al. (2008) reported that Wnt/ $\beta$ catenin signaling was important for the regulation of two key tight junction proteins, claudin 3 and claudin 5. In contrast, Daneman et al. (2009) reported no effect of down regulation of the $\mathrm{Wnt} / \beta$-catenin pathway on regulation of the tight junction proteins, occludin and claudin 5 in E1 1.5 endothelial-specific $\beta$ catenin mutants. It is not clear whether this difference was due to the mutants used or the age at which they were examined. The $\mathrm{Wnt} / \beta$-catenin pathway was found to be active in many endothelial cells of developing brain from as early as E9.5; expression declined after E15.5 to a lower level that was maintained in the neonatal period, but by adulthood expression was rare (Liebner et al., 2008).

There is general agreement that Wnt ligands are present in early neural progenitors of the ventricular zone with some regional specificity (Stenman et al., 2008; Daneman et al., 2009). Thus vascular Wnt activation temporally correlates with the expression of Wnt7a and Wnt7b in the developing forebrain and in the ventral and intermediate spinal cord; Wnt 4 in the dorsal and intermediate spinal cord; and Wnt1, Wnt3, and Wnt3a throughout the dorsal neural tube (Daneman et al., 2009).

\section{MENINGEAL BARRIER}

At the blood-brain interface over the outer surface of the brain within the pia-arachnoid, the blood vessels also have tight junctions between the endothelial cells, but their cellular transport properties have been little studied. Other important interfaces are between the CSF and brain interstitium at the inner (ventricular) and outer (subarachnoid) spaces. In the adult, cells lining these interfaces are linked by gap junctions, which do not significantly hinder intercellular passage of molecules. However, in the early stages of brain development the cells lining these interfaces are more heterogeneous and are linked by strap junctions, which occlude the intercellular space except to the smallest molecules; this additional barrier provides a specific internal milieu for the developing brain, in contrast to free exchange between CSF and brain present in the adult (Fossan et al., 1985; Saunders, 1992; Balslev et al., 1997a).

\section{CHOROID PLEXUSES}

The molecular make-up of tight junctions of the blood-CSF barrier is less well-known (Wolburg et al., 2001). A recent study of tight junction protein expression in mouse embryos (E15) and adult choroid plexus (Liddelow et al., 2012) has shown that several key junctional genes are expressed at a higher level in embryos than in the adults, whereas for several other genes the reverse is the 
case (Table 1). This is consistent with previous findings that the fundamental functional basis of this barrier, namely occlusion of the paracellular diffusion pathway, is well established from the earliest stages of differentiation of the choroid plexuses (Bauer et al., 1993; Ek et al., 2003, 2006).

\section{APPARENT INCREASED PERMEABILITY OF BARRIERS IN DEVELOPING BRAIN \\ SMALL LIPID INSOLUBLE MOLECULES}

Studies have been carried out in fetuses and newborn of many species using classical radiolabeled physiological permeability markers, sucrose and inulin. These all showed that the earlier in development experiments were conducted, the higher was the apparent permeability (expressed as brain-plasma and CSFplasma ratios e.g. Habgood et al., 1993). This was interpreted by some as evidence for brain barrier "immaturity" (see Saunders, 1992, for review of earlier studies). However, extensive ultrastructural studies show that the tight junctions at brain barrier sites are formed very early in development (Møllgård and Saunders, 1975; Møllgård et al., 1976; Tauc et al., 1984; Ek et al., 2001, 2003, 2006). This discrepancy between well-formed tight junctions and higher apparent permeability in the developing brain has only recently been resolved by the use of small lipid insoluble molecules (mainly dextrans of different molecular size) which can be visualized at the electron microscopical level (Ek et al., 2001, 2003, 2006). At least in short term experiments, tight junctions in cerebral blood vessels and choroid plexus epithelial cells (plexus blood vessels are fenestrated and allow the movement of molecules between the blood and basement membrane) are impermeable to molecules as small as sucrose even when blood vessels first penetrate the brain (Figure 3). The observed drop in the concentration ratios can be explained by the initial rapid increase in ventricular volume (occurring as part of normal brain development), which dilutes the entering permeability markers and a low rate of CSF secretion.

Table 1 |Tight junction protein genes enriched in mouse lateral ventricular choroid plexus.

\begin{tabular}{lll}
\hline Gene symbol & GenBank ID & Fold change \\
\hline TRANSMEMBRANE & & \\
(A) & & \\
Pcdh18 & BC052198 & 6.9 \\
Cdh5 & BC054790 & 4.3 \\
Cmtm3 & AY241870 & 4.0 \\
Cdh2 & AB008811 & 3.4 \\
Jam3 & BC024357 & 3.2 \\
Cldn11 & BC021659 & 2.0 \\
(B) & & \\
lgsf5 & BC004806 & 9.6 \\
Cldn2 & BC085494 & 4.3 \\
Marveld3 & BC025851 & 4.2 \\
Cldn12 & BC024057 & 2.1 \\
\hline
\end{tabular}

List of proteins known to be associated with tight junctions whose genes were up-regulated in either the embryo $(A)$ or the adult (B) expressed as fold change compared to levels in other age. From Table 4 in Liddelow et al. (2012).
Subsequent opening of the inner ventricular system to the subarachnoid space and onset of CSF drainage via arachnoid villi (Jones, 1980; Jones and Sellars, 1982; Jones and Bucknall, 1988) with increasing CSF secretion add to further dilution of markers entering CSF. A similar process affects brain distribution of markers because of the presence of a transient CSF-brain barrier at the level of the neuroependymal cells lining the cerebral ventricles (Fossan et al., 1985; Møllgård et al., 1987).

\section{PROTEIN PERMEABILITY}

The protein concentration in fetal CSF is high compared to the adult (Dziegielewska and Saunders, 1988; Saunders et al., 1999). Some authors have interpreted this as evidence that brain barriers (both blood-CSF and blood-brain barrier) are immature in the embryo (Adinolfi et al., 1976; Adinolfi and Haddad, 1977; Ramey and Birge, 1979; Adinolfi, 1985). However, there is good experimental evidence that this high protein concentration is a result of transcellular transfer of plasma proteins across choroid plexus epithelial cells (Dziegielewska et al., 1980, 1991; Habgood et al., 1992; Knott et al., 1997; Liddelow et al., 2009, 2011a) reinforced by the slow turnover of CSF in the developing brain (Bass and Lundborg, 1973; Johanson and Woodbury, 1974) which would be expected to allow proteins entering the CSF via the choroid plexuses to accumulate to a greater extent than in the adult (Johansson et al., 2008). These authors also provide a novel
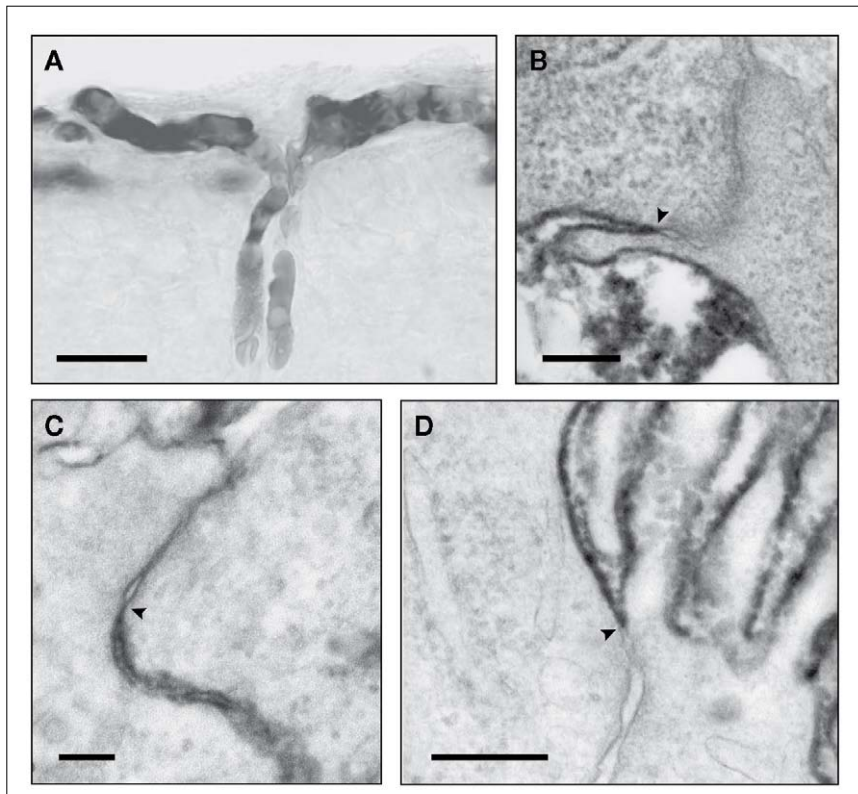

FIGURE 3 | Light (LM) and electronmicrographs (EM) of early developing brain blood vessels and choroid plexus, illustrating functional effectiveness of tight junctions. (A) (LM) and (B) (EM) of newborn opossum injected intraperitoneally (i.p.) with $3 \mathrm{kDa}$ biotin dextran. Reaction product confined to vessel lumen (A) not passing through tight junctions [(B), arrowhead]. (C) Newborn opossum choroid plexus injected i.p. with $3 \mathrm{kDa}$ biotin dextran which does not pass through tight junction (arrowhead). (D) E15 rat, tracer injected into lateral ventricle. Choroid plexus tight junctions (arrowhead): no passage of tracer between cells. Images: (A,B) from Ek et al. (2006); (C,D) from Ek et al. (2003). Scale bars: (A), $25 \mu \mathrm{m}$; (B), $200 \mathrm{~nm}$; (C), $100 \mathrm{~nm}$; (D), $300 \mathrm{~nm}$. 
interpretation of the results by pointing out that the content of protein in the CSF should be taken into account rather than concentration. Concentration is a function of amounts and the volume in which the protein is distributed. Changes in the volume of distribution would change the concentration without altering the actual amount (see previous section). A general and approximate calculation comparing the amounts of protein in fetal and adult CSF of several species demonstrated that in adult CSF there is actually more protein than in the fetus in spite of CSF protein concentration being much higher in the younger brain (Johansson et al., 2008).

\section{PROTEIN TRANSPORT FROM BLOOD TO CSF ACROSS THE CHOROID PLEXUSES}

Transcellular transfer of plasma proteins was first described over 30 years ago (Dziegielewska et al., 1980). It was apparent from the outset that the transfer exhibited a striking degree of developmentally regulated specificity. In particular it was shown that the level of transport of albumin depended upon the species of albumin and the animal species in which it was studied. It is important to make the distinction between proteins made by the choroid plexus itself, e.g., transthyretin. (Schrieber et al., 1990), and those proteins transferred between the blood and the CSF. However, transthyretin is also transferred from blood plasma (Dziegielewska et al., 1980). Thus in the original experiments, fetal sheep (E60, term is 150 days) transferred their own albumin and bovine albumin to the same steady state level, whereas human and chicken albumins appeared to be discriminated to the extent that their steady state CSF/plasma concentration ratios were about half that of native albumin. A similar phenomenon has been described for albumins in embryonic and neonatal rats (Habgood et al., 1992; Johansson et al., 2006) postnatal opossum (Knott et al., 1997) and in postnatal mice (unpublished). A common characteristic of these experiments is that later in development the species specificity for different albumins disappears (Dziegielewska et al., 1980; Habgood et al., 1992; Knott et al., 1997) but it could also be experimentally abolished by chemical modification of the protein (Habgood et al., 1992; Knott et al., 1997).

Recent application of physiological and molecular techniques to the study of specific protein transport in the choroid plexus revealed that the plexus epithelial cells contain a number of receptor-/protein-binding-like molecules that have an affinity for albumin and may be the mechanism by which protein is transferred from blood to CSF (Liddelow et al., 2011b). Three genes: Sparc, Glycophorin A (Gypa), and C $(G y p c)$, were identified as those whose gene products are candidates to target plasma proteins to choroid plexus cells. Sparc and Gypa were identified by immunocytochemistry in choroid plexus epithelial cells in the embryo, subcellular distribution consistent with transport of albumin from blood to CSF, as is illustrated in Figure 4. In adult plexus this pattern of immunostaining was absent. This mechanism has been shown to be more specific for individual plasma proteins early in brain development and responsive to changes in concentrations of proteins in plasma presumably as part of a normal homeostatic mechanism (Liddelow et al., 2009). In contrast to the one-way (blood to CSF) transport of proteins across the choroid plexus epithelial cells, inert dextrans are transported in both

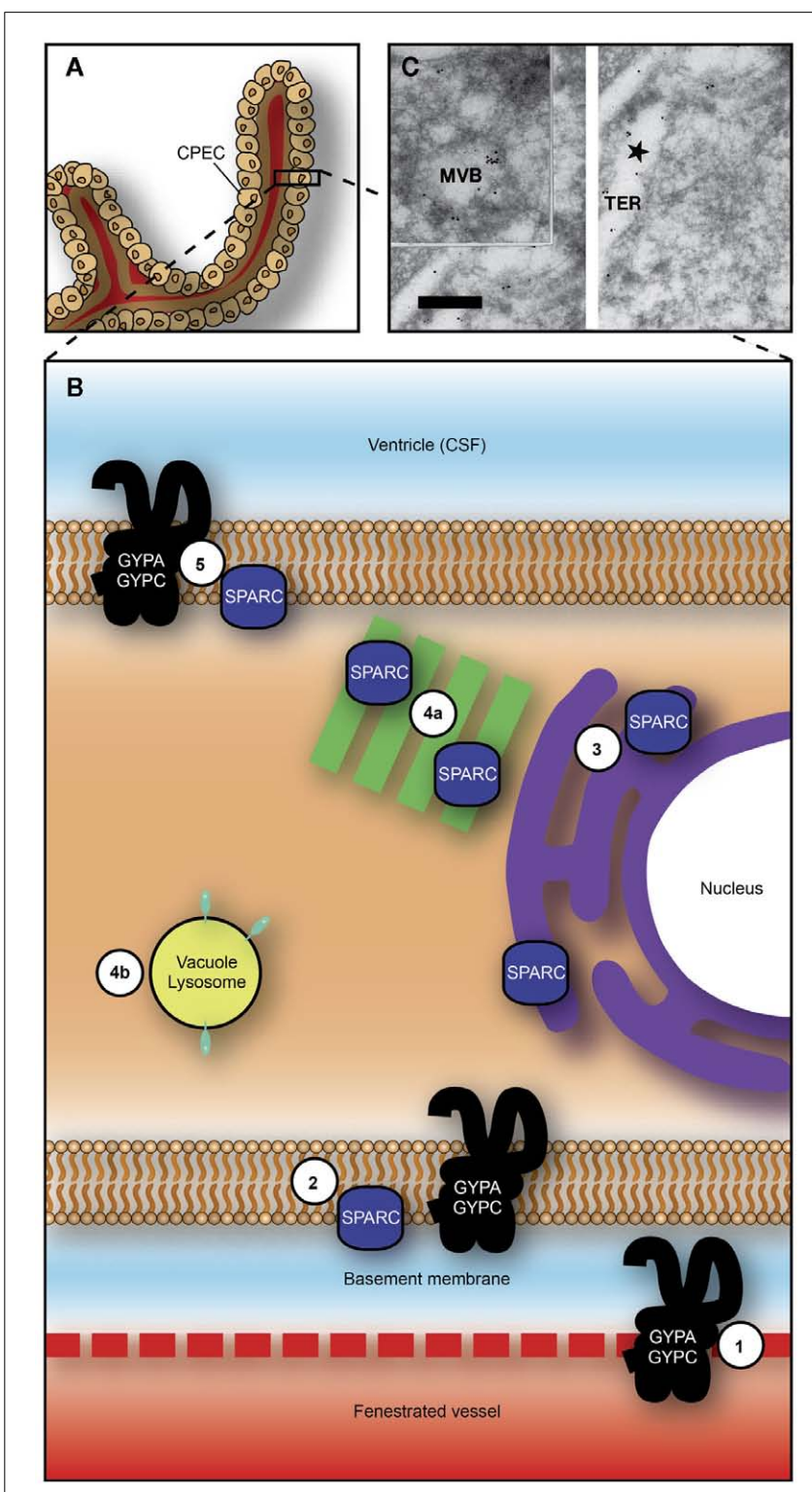

FIGURE 4 | Proposed transepithelial pathway for albumin through choroid plexus epithelial cells. (A) Whole choroid plexus showing single layer of epithelial cells sitting on thick basement membrane (see also Figure 1C). (B) Suggested routes of albumin from plasma into CSF across the choroid plexus epithelium. GYPA/C in endothelial cells may deliver albumin to basement membrane (1) from where it can be taken up into plexus epithelium by GYPA/C or SPARC (2). Albumin may then travel along a SPARC-specific pathway through tubulocisternal endoplasmic reticulum [3, and see (C)] and Golgi (4a), or via a VAMP-mediated pathway in vacuoles, lysosomes, or multivesicular bodies [4b, and see (C)]. On apical surface of plexus epithelium, GYPA/C may be involved in efflux of protein from the cell into CSF (5). In adult, lack of immunoreactivity in endoplasmic reticulum and Golgi and increased expression of gene products for VAMP molecules, suggest that majority of transport occurs via VAMP-mediated vesicular transport (4b). (C) Transmission electron micrograph of ultracryosection from E60 fetal sheep choroid plexus (Balslev et al., 1997b). Immunolabeled human albumin $6 \mathrm{~nm}$ particles and sheep albumin $12 \mathrm{~nm}$ gold particles are shown to co-localize within the tubulocisternal endoplasmic reticulum. Abbreviations: CPEC, choroid plexus epithelial cell; CSF, cerebrospinal fluid; GYPA, glycophorin A; GYPC, glycophorin C; MVB, multivesicular body; TER, tubulocisternal endoplasmic reticulum. Scale bar: $0.2 \mu \mathrm{m}$ in (C). Image from Liddelow et al. (2012). 
directions (blood to CSF and CSF to blood) with twice as many cells staining for dextrans when administered intraventricularly than intraperitoneally (Figure 5).

The proteins transported into CSF across the choroid plexuses have been suggested to have three functions in brain development: (i) some of the proteins are taken up by neural cells present in the ventricular zone that are in contact with the CSF and may have some specific involvement in features of brain development such as mitosis, migration, and differentiation (Stolp et al., 2011), (ii) they may act as carriers for growth factors, hormones and vitamins, (iii) the high concentration of proteins in CSF early in brain development may exert a colloid osmotic pressure within the ventricles, thus promoting fluid transfer across the choroid plexuses and contributing to developmental expansion of the ventricles (essential for normal brain growth, see Saunders et al., 1999). However, it also needs to be considered that proteins such as albumin are known carriers of heavy metals and drugs, thus in the presence of such toxic molecules this normal mechanism may render the developing brain more vulnerable to such agents (Saunders et al., 2010; Ek et al., 2012).

\section{UPTAKE FROM CSF INTO BRAIN}

Once proteins have transferred across the choroid plexus into CSF, some are taken up into cells in the brain. For example some neuroependymal cells lining the cerebral ventricles take up proteins such as albumin and the fetal protein fetuin (Dziegielewska et al., 2000). The initial cells that form the first layers of the neocortex in the embryo take up fetuin via apical dendrites that make contact
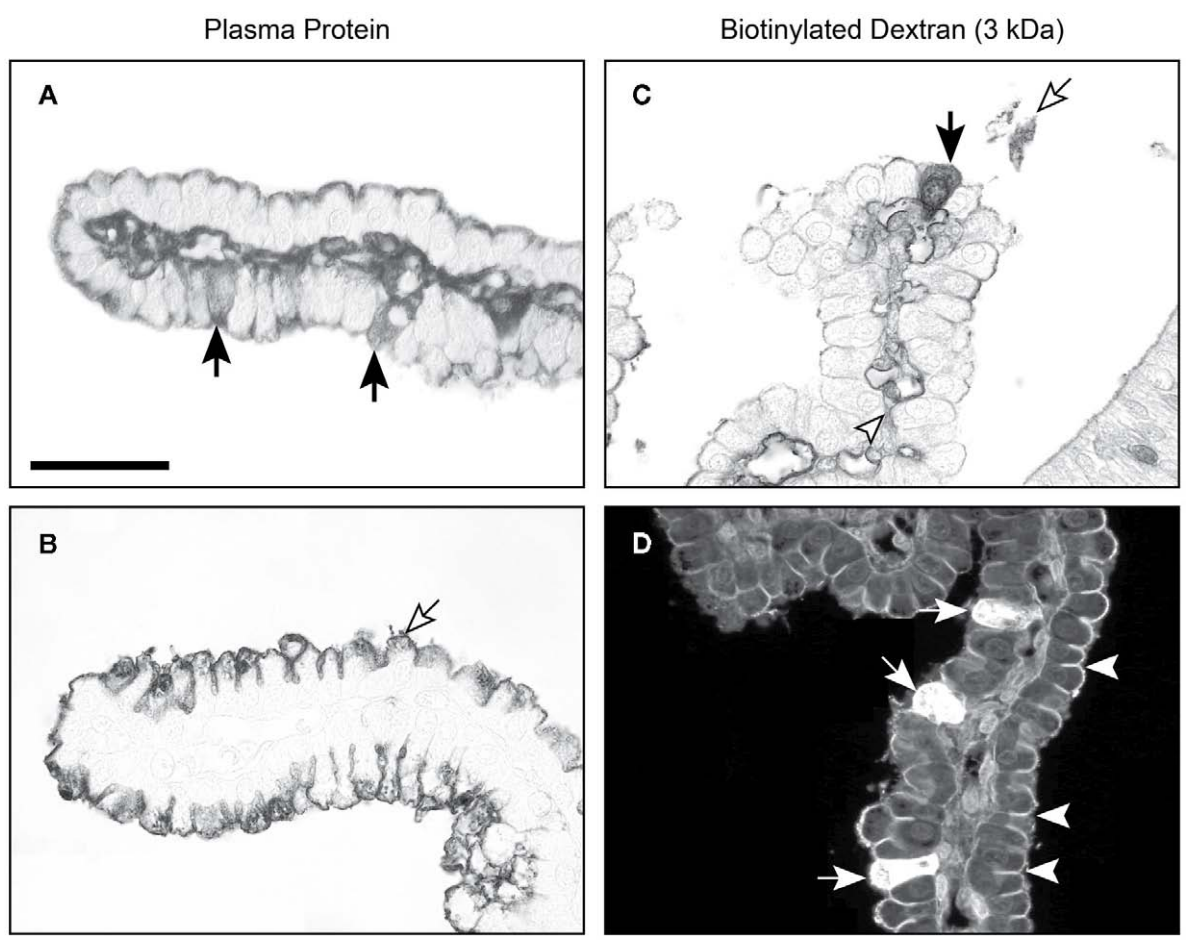

\begin{tabular}{c|ccc|ccc}
\hline \multicolumn{10}{|c|}{ Bovine Fetuin } & \multicolumn{3}{c}{ BDA (3 kDa) } \\
\cline { 2 - 8 } Route of administration & $n$ & Cells & $\%$ Total $^{*}$ & $n$ & Cells & $\%$ Total $^{*}$ \\
& 3 & $114 \pm 12$ & $4.4 \pm 0.4$ & 4 & $15 \pm 5$ & $0.5 \pm 0.2$ \\
intraperitoneal & 3 & 0 & 0 & 4 & $32 \pm 6$ & $1.0 \pm 0.2$ \\
\hline intraventricular & 3
\end{tabular}

FIGURE 5 | Cellular localization of fetuin and inert biotin dextran (3 kDa) in postnatal (P9) Monodelphis domestica. Light micrograph showing the localization of bovine fetuin (A,B) detected with its antibodies and biotin dextran (C,D) detected with $A B C$ ( $A B C$ kit, Vector Laboratories), in coronal sections of lateral ventricular choroid plexus. (A) Twenty-four hours after intraperitoneal injection of bovine fetuin, specific epithelial cells of the plexus (filled arrows) were found containing the protein. (B) Bovine fetuin was injected into the lateral ventricle and left for $10 \mathrm{~min}$. The protein was not detected in any cells of the plexus, or in the lumen of blood vessels in the plexus stroma. Protein can be seen on the CSF side of the epithelial cells, precipitated on the brush border (unfilled arrow). (C) Forty-five minutes after intraperitoneal injection with BDA ( $3 \mathrm{kDa})$, the probe can be seen in specific epithelial cells of the choroid plexus (filled arrow), as well as in the blood vessel lumen (arrowhead) and precipitated in the CSF (unfilled arrow). (D) Ten minutes after intraventricular injection with Fluorescein-conjugated BDA ( $3 \mathrm{kDa}$ ), more epithelial cells take up the probe (filled arrows) following CSF injection compared with intraperitoneal injection (C). Penetration of the fluorescent probe between epithelial cells is stopped by the presence of tight junctions (examples highlighted by arrowheads). (E) Uptake of bovine fetuin and BDA ( $3 \mathrm{kDa}$ ) into choroid plexus epithelial cells in P9 Monodelphis following intraperitoneal or intracerebroventricular injection; mean $\pm S E M$, numbers of immunostained cells. P9 Monodelphis injected with fetuin and BDA (3 kDa) intraperitoneally or into one lateral ventricle. *Percentage of all cells counted. $n$ is the number of individual brains used in the study; BDA (3 kDa), biotinylated dextran amine MW $3 \mathrm{kDa}$. Scale: $50 \mu \mathrm{m}$ (A-D). From Liddelow et al. (2009) Figure 3 and Table 7. 
with the dorsal surface of the cortex (Dziegielewska et al., 2000). However, this uptake has been little studied and it is not clear whether the proteins themselves are functionally important or bound ligands such as hormones and growth factors. A recent publication indicated that the number of plasma protein positive cells in the ventricular zone of a fetal mouse can be increased following an inflammatory response of the dam indicating that protein uptake into the brain can be physiologically responsive to its changing environment of Stolp et al. (2011).

\section{INFLUX MECHANISMS ACROSS BRAIN BARRIERS IN THE DEVELOPING BRAIN \\ AMINO ACID TRANSPORT}

Davson (1967) summarized the available evidence on exchange of metabolically important materials between blood and brain in developing animals. On the one hand he accepted Bakay's (1953) results using ${ }^{32} \mathrm{P}$, which showed decreasing uptake with age, as a qualitative indication of the state of the blood-brain barrier. On the other hand he pointed out that greater metabolic incorporation in the developing brain would also contribute to the experimental findings. Bakay (1953) himself discussed both mechanisms and reconciled them by suggesting that his results indicated the presence of a blood-brain barrier in the fetus (rabbit) but that it was more permeable than in the adult. There were similar discussions of the results of experiments studying the entry of amino acids into the developing brain (Himwich et al., 1957; Roberts et al., 1959; Purpura and Carmichael, 1960; Lajtha and Toth, 1961; Seta et al., 1972; Baños et al., 1978) in which the entry of several amino acids was found to be greater in younger animals than in the adult. Kuttner et al. (1961) attempted to get round the difficulty of distinguishing between cerebral endothelial cell transport and metabolic incorporation into brain tissue by studying the uptake of $\alpha$-aminoisobutyric acid, which is transported but is metabolically inert. They reported a much greater uptake of this amino acid in neonatal rabbits compared to adults but interpreted this as indicating "lesser effectiveness" of the blood-brain barrier for amino acids in young animals; this interpretation was reiterated by others (e.g., Lee, 1971). Later studies using the Oldendorf (1971) short pass technique or modifications of the method, allowed separation of entry into the brain from metabolic incorporation. This was done by exposing the cerebral circulation of developing animals to test amino acids and other metabolically active compounds for only a brief period. These experiments showed that many amino acids and other metabolically active compounds were transported into the developing brain at much higher rates than in the adult and was interpreted as reflecting the greater metabolic demand of the developing brain rather than immaturity of the blood-brain barrier (Braun et al., 1980; Cornford et al., 1982; Pardridge and Mietus, 1982; Lefauconnier and Trouvé, 1983). However, some authors have continued to suggest that this greater uptake may reflect barrier immaturity (see Watson et al., 2006).

It is now clear that the transport mechanisms in the brain barrier interfaces determine the composition of the internal environment of developing brain and supply essential nutrients and other molecules important for growth and differentiation of the brain. Figure 6 summarizes which inward (blood-brain) transport

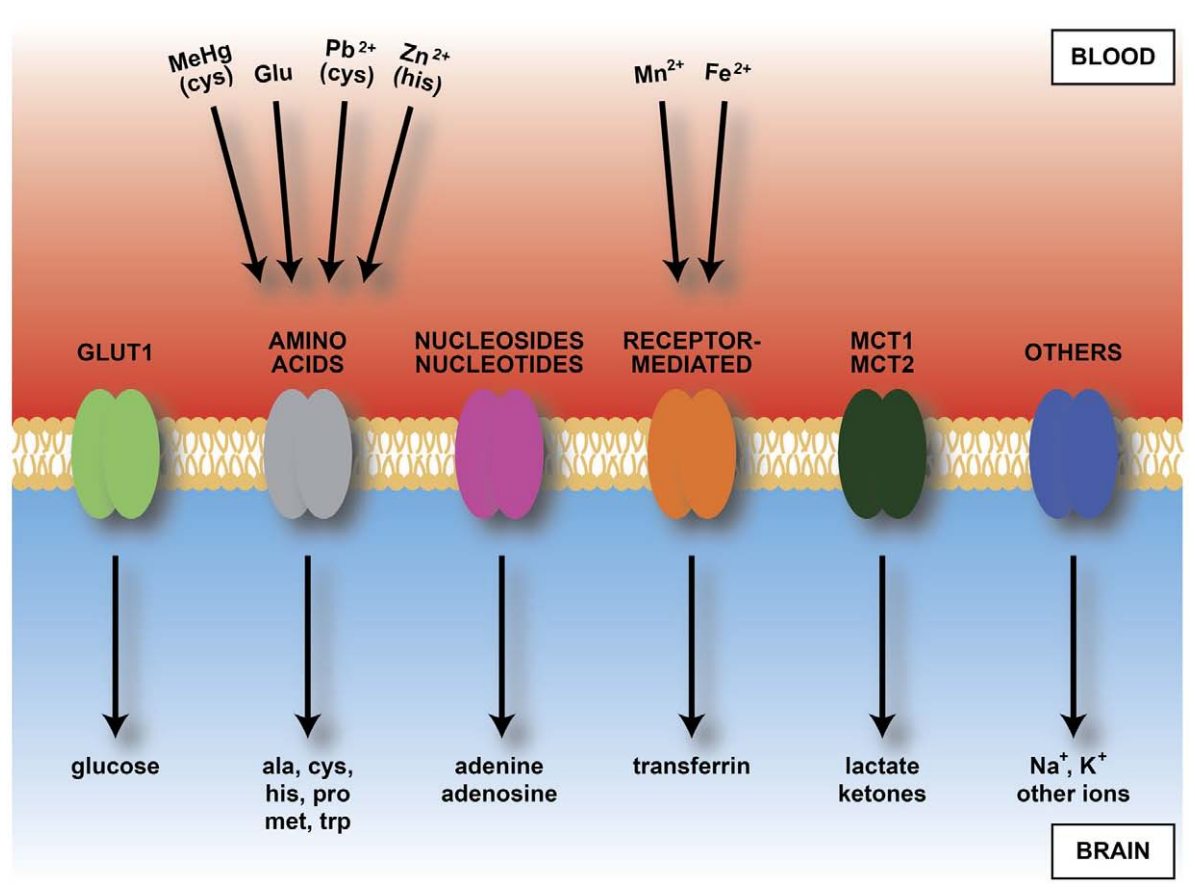

FIGURE 6 | Diagram of main inward transporters in cerebral endothelial cells. Heavy metals bind to some amino acids and transferrin receptors. Because of vulnerability of developing brain to heavy metals this transport may contribute to fetal or newborn neurotoxicity. Compare Table 2, which shows transporters expressed in endothelial cells from developing brain, including those up-regulated compared to adult. Abbreviations: ala, alanine; cys, cysteine; $\mathrm{Fe}^{2+}$, iron; Glu, glutamate; his, histidine; MCT, monocarboxylate transporter; MeHg, methyl mercury; met, methionine; $\mathrm{Mn}^{2+}$, manganese; $\mathrm{Pb}^{2+}$, lead; pro, proline; trp, tryptophan; $\mathrm{Zn}^{2+}$, zinc. 
mechanisms have been shown to be functional in the fetal and newborn brain. Much of the evidence for function of many of these mechanisms was published some time ago and is outlined above (see also reviews by Saunders, 1992; Saunders et al., 2010; Saunders and Habgood, 2011; Liddelow et al., 2012).

The information that has been lacking until recently is that on the presence and expression level of transporters in the brain barrier interfaces in the developing brain. This is now available from expression studies of isolated cerebral endothelial cells from neonatal mice (Daneman et al., 2010a) and from choroid plexus of fetal mice compared to the adult (Liddelow et al., 2012). Table 2 (from Daneman et al., 2010a) shows a summary of influx transporters that are up-regulated in the neonatal mouse compared to

Table 2 | Expression of transporters in endothelial cells from neonatal mouse brain.

\begin{tabular}{l}
\hline Gene ID Description \\
\hline BBB ENRICHED INFLUXTRANSPORTERS \\
(A)
\end{tabular}

\begin{tabular}{ll} 
Slc1a1 & Glutamate \\
Slc1a4 & Alanine, serine, cysteine, threonine \\
Slc2a1 & Glucose \\
Slc6a6 & Taurine, $\beta$-alanine \\
Slc6a17 & AAs, betaine, taurine, creatine \\
Slc7a1 & Cationic AAs \\
Slc7a3 & Cationic AAs \\
Slc7a5 & Neutral AAs \\
Slc12a6 & K' $^{+}{ }^{-}$ \\
Slc16a1 & Monocarboxylates \\
Slc16a2 & Thyroid hormones \\
Slc16a4 & Monocarboxylates \\
Slc19a3 & Thiamine \\
Slc25a20 & Acylcarnitines \\
Slc25a33 & Putative \\
Slc30a1 & Zinc \\
Slc31a1 & Copper \\
Slc35f2 & Putative \\
Slc38a3 & Glutamate, Na ${ }^{+}$ \\
Slc38a5 & Neutral AAs \\
Slc39a10 & Zinc \\
Slc40a1 & Iron \\
Slc46a3 & Putative \\
Slco1a4 & Organic anions (e.g., bile acids) \\
Slco1c1 & Thyroid hormones \\
Slco2b1 & Prostaglandins, organic anions \\
(B) & \\
Abca5 & Multidrug resistance protein 1 \\
Abcb1a & Multidrug resistance associated protein 4 \\
Abcc4 & \\
Abcg2 & \\
\hline & \\
\hline & \\
&
\end{tabular}

(A) Influx transporters. Up-regulated glutamate transport probably explains neurotoxic effects of glutamate in immature brain, rather than barrier deficiency (compare Figure 6). (B) Efflux transporters (compare Figure 7). Data from Daneman et al. (2010a). AA, amino acid. the adult. Table 3 shows similar data from fetal mouse choroid plexus. It is technically difficult to demonstrate how functionally active these genes are because embryos of common experimental animals are very small. In newborn rats and rabbits several amino acid transporters were shown to be functional at a higher rate than in the adult (Saunders and Habgood, 2011). Another example of greater transport in developing brain is inward transport of phosphorylated lysosomal enzymes by the transporter M6P/IGF2R in newborn mice. This transport is progressively lost with age and by adulthood is undetectable (Urayama et al., 2008). The findings also help to explain a number of important previous observations on developmentally different effects of amino acids on brain function. For example it was reported many years ago that glutamate is toxic to the brain if administered in the neonatal period (Olney and Ho,

Table 3 | Expression of influx transporters in embryonic mouse choroid plexus.

\begin{tabular}{lll}
\hline Gene symbol & GenBank ID & Fold change \\
\hline
\end{tabular}

\section{SOLUTE CARRIERS}

\section{(A)}

Slc16a10

Slc6a15

Slc40a 1

Slc7a11

Slc4a1

Slc6a13

Slc1a4

SIc38a4

Slc6a6

Slc4a4

Slc7a1

Slc39a8

(B)

Slc5a5

S/c39a4

SIC41a2

SIc24a4

S/c28a3

SIc24a5

Sic9a7

Slc6a17

Slco1c1

SIc4a10

Slc39a14

Slc35f3

SIC13a4

Slc37a2

Slco1a5

Slc39a12

Slc46a1

Slc25a35

Slc22a5

\begin{tabular}{|c|c|}
\hline BC052877 & 66.8 \\
\hline AY149280 & 11.4 \\
\hline AF231120 & 9.6 \\
\hline AY766236 & 7.1 \\
\hline BC053429 & 5.5 \\
\hline BC029637 & 4.6 \\
\hline BC043483 & 4.4 \\
\hline AY027919 & 4.2 \\
\hline L03292 & 4.1 \\
\hline AF141934 & 4.1 \\
\hline M26687 & 4.1 \\
\hline BC006731 & 3.3 \\
\hline AF235001 & 13.6 \\
\hline BC023498 & 9.6 \\
\hline NM_177388 & 8.5 \\
\hline AY156046 & 7.8 \\
\hline BC013783 & 6.9 \\
\hline AB085629 & 6.1 \\
\hline BC058750 & 5.8 \\
\hline AY155578 & 3.5 \\
\hline AY007379 & 5.2 \\
\hline AK220501 & 5.0 \\
\hline AB177995 & 4.0 \\
\hline BC115965 & 3.9 \\
\hline ВС089161 & 3.9 \\
\hline AF121081 & 3.5 \\
\hline AF240694 & 3.4 \\
\hline BC089362 & 3.3 \\
\hline ВС057976 & 3.2 \\
\hline BC019996 & 3.1 \\
\hline AF110417 & 3.0 \\
\hline
\end{tabular}

Solute carriers up-regulated in either the embryo (A) or the adult (B). From Table 5 in Liddelow et al. (2012). 
Table 4 | Comparison of expression of influx transporters in mouse E15 choroid plexus and published reports on transport function in the developing brain.

\begin{tabular}{|c|c|}
\hline Transporter & Transport function \\
\hline Slc16a10 & lodothyronines $\mathrm{T3}, \mathrm{T} 4^{1}$ \\
\hline Slc6a15 & Neutral amino acids ${ }^{2}$ \\
\hline Slc40a1* & $\operatorname{Iron}^{3}$ \\
\hline Slc7a11 & Cysteine, glutamate ${ }^{2}$ \\
\hline Slc4a1 & Anion transporter ${ }^{4},\left(\mathrm{Cl}^{-}-\mathrm{HCO}_{3} \text { exchange }\right)^{5}$ \\
\hline Slc6a13 & GABA transporter ${ }^{6}$ \\
\hline Slc1a4 & Glutamate, neutral amino acids ${ }^{7}$ \\
\hline S/c38a4 & Acidic and neutral amino acids ${ }^{2,7}$ \\
\hline Slc6a6 & Taurine $^{2}$ \\
\hline Slc4a4 & $\mathrm{Na}^{+}-\mathrm{HCO}_{3}^{-}$cotransporter ${ }^{4}$ \\
\hline Slc7a1 & Acidic amino acids ${ }^{2}$ \\
\hline Slc39a8 & Zinc transporter 8 \\
\hline
\end{tabular}

Only Slc4a4, Slc7a11, and Slc40a1 have previously been identified in choroid plexus. Superscript numbers indicate published studies showing transport into developing brain or CSF. *Gene product ferroportin-1 identified in choroid plexus. ${ }^{1}$ Porterfield and Hendrich (1992), ${ }^{2}$ Lefauconnier and Trouvé (1983), ${ }^{3}$ Morgan and Moos (2002), "4 Damkier et al. (2010), ${ }^{5}$ Amtorp and Sørensen (1974), ${ }^{6}$ Al-Sarraf (2002), ${ }^{7}$ Al-Sarraf et al. (1997), ${ }^{8}$ Chowanadisai et al. (2005). From Table 6 in Liddelow et al. (2012).

1970) which some attributed to "immaturity" of the blood-brain barrier (Viña et al., 1997). However, it can now be seen that the barrier contribution to toxicity is much more likely to be due to greater transport by, e.g., Slcla4, see Table 4, which summarizes data on expression of influx transporters and published reports on transport function in the developing brain.

\section{AQUAPORINS}

There is also good evidence for appearance of the key water channel aquaporin-1 in very early choroid plexus epithelial cells (Johansson et al., 2005). The development of ion gradients between CSF and plasma in the fetal brain suggests that at least some ion pumps are active across the blood-CSF barrier (see Saunders, 1992). Molecular expression studies in embryonic choroid plexus confirm that some ion exchange mechanisms are present early in development (Johansson et al., 2007; Liddelow et al., 2012) and probably also across the blood-brain barrier early in development (Daneman et al., 2010a). Little is known of what happens if these mechanisms become dysfunctional or develop abnormally.

\section{EFFLUX MECHANISMS ACROSS BRAIN BARRIERS IN THE DEVELOPING BRAIN}

An important mechanism in the adult brain at both the bloodbrain and blood-CSF barriers are ATP-binding cassette (ABC) efflux transporters (Hartz and Bauer, 2011). These transporters are summarized in Figure 7. They exclude a large number of toxic but also potentially therapeutic compounds from the brain; thus knowledge of their presence and effectiveness in the developing brain is essential for assessing what risk drugs and toxins may pose. Immunohistochemical studies of P-glycoprotein in human fetuses report its presence in cerebral endothelial cells as early as
Table 5 | Efflux (ABC) transporter expression in embryonic (A) and adult (B) mouse choroid plexus.

\begin{tabular}{llll}
\hline Gene & Other IDs & Array & qPCR \\
\hline (A) & & & \\
Abcb3 & TAP2 & - & 16.5 \\
Abcb6 & UMAT, MTABC3 & 2.6 & 8.1 \\
Abcg2 & BCRP & - & 15.8 \\
Abcg5 & Sterolin1, White3 & 14.1 & 44.8 \\
Abcg8 & Sterolin2, White4 & 3.4 & 20.3 \\
(B) & & & \\
Abca2 & & 3.5 & 22.4 \\
Abca4 & ABCR, RP19, RIM & 9.7 & 12.9 \\
Abca5 & & 2.5 & 1.4 \\
Abca7 & ABCX & 4.5 & - \\
Abcb9 & TAPL & 2.8 & 1.8 \\
Abcc1 & MRP, MRP1 & 2.3 & - \\
\hline
\end{tabular}

Most enriched genes during development of the mouse lateral ventricular choroid plexus in the embryo or adult. Expression of a further 35 genes was detected at both ages with no difference in expression levels (not shown). Array targets were considered enriched with fold changes equal or greater than 2. From Table 7 in Liddelow et al. (2012).

8 weeks gestation (Schumacher and Møllgård, 1997). Expression and immunohistochemical studies of brain and choroid plexuses in embryonic and adult rats (Ek et al., 2010) have shown that known key efflux transporters, multidrug resistance-associated proteins 1 and 4, P-glycoprotein and breast cancer resistance protein (BCRP) are expressed early in both brain and in choroid plexus epithelial cells and that their expression is differentially regulated both with respect to individual efflux transporters and age. It is particularly striking that BCRP is expressed at the highest level in embryonic rat choroid plexus (20-fold compared to adult). In the brain practically no change in expression level for BCRP between the embryo and adult was found (Ek et al., 2010). Many of these efflux mechanisms are present and functionally effective in the placenta (see Saunders et al., 2010). Data on efflux transporters in embryonic and adult mouse cerebral endothelial cells and choroid plexus are summarized in Tables $\mathbf{3 B}$ and 5. Little is known about the function of efflux transporters in the human newborn brain, but it may be that because of the loss of the protection provided by the placenta, after birth the neonatal brain may be more vulnerable to entry of drugs and toxins.

\section{NEUROPATHOLOGY OF BARRIER MECHANISMS IN THE DEVELOPING BRAIN INFLAMMATION}

The blood vessels in the developing brain are undoubtedly more fragile than in the adult, which probably explains many of the claims of barrier immaturity or leakiness, stemming from experiments in which excessive volumes of fluid have been injected into fetuses (see Saunders, 1992 for review). A specific example of susceptibility of cerebral blood vessels in the developing brain is the effect of lipopolysaccharides on permeability of blood vessels in white matter at a critical stage of brain development 
(Stolp et al., 2005a,b). These blood vessels show a leakage of plasma proteins, demonstrated in postnatal rats and opossums at a stage of brain development equivalent to 22-28 weeks gestation in humans (Stolp and Dziegielewska, 2009). In a clinical context if a mother develops an infection, the fetus may be born prematurely and in some cases white matter damage has been observed with the development of cerebral palsy (Dammann and Leviton, 1997; Yoon et al., 2000). Leakage of proteins from plasma into white matter in the presence of uterine infection has been suggested to be part of the etiology (Stolp and Dziegielewska, 2009). The possible role of barrier dysfunction in the developing brain and subsequent development of neurological/neuropsychiatric disorders such as schizophrenia, Alzheimer's disease and multiple sclerosis has been reviewed (Stolp and Dziegielewska, 2009). Most studies seem to have concentrated on changes in permeability to large or small molecules and in properties of tight junctions. The possibility of functionally important changes in influx (Figure 6) or efflux (Figure 7) mechanisms following a pathological insult to the developing brain scarcely seems to have been considered.

\section{KERNICTERUS}

Ek et al. (2012) have discussed some possible reasons for the persisting belief amongst for, example neuropathologists and some physiologists and pediatricians that the blood-brain barrier in the developing brain is immature or "leaky." A general reason was given by Barcroft (1938) who expressed the view "There is no reason why the brain of the embryo should require an environment of very great chemical constancy. It will of course require a certain minimum of the various materials necessary for growth, but otherwise on first principles we might suppose that the good things of life may exist in and may vary in the fetal blood to an extent much greater than the maternal." Bakay (1956) expressed a similar view. However, teleological arguments are hardly a rigorous way of determining the mechanism of physiological functions. It seems likely that the proposal that the blood-brain barrier in the fetus and newborn is immature stems in part from a view that prevailed in the middle of the last century that kernicterus (brain damage from excess unconjugated bilirubin in the circulating blood) occurred in prematurely born infants but less commonly in term babies and never in adult, because of immaturity of the blood-brain barrier (e.g., Bakay, 1953; Lee, 1971). This appears to have been first proposed by Spatz (1934, cited by Davson, 1967). Once it became realized that unconjugated bilirubin binds to plasma albumin it was increasingly appreciated that a key determinant of whether or not kernicterus occurred was whether or not this binding capacity was exceeded (e.g., Bakay, 1968). However, some have continued to cite claims of immaturity of the blood-brain barrier to small molecules as contributing to kernicterus in newborn infants (Barrett et al., 2010). This overlooks the fact that unconjugated bilirubin is lipid soluble and will enter the brain unless bound to plasma albumin. Also greater permeability to small molecules in the immature brain is apparent rather than real as it is due to slow turnover of CSF (see Apparent Increased Permeability of Barriers in Developing Brain above). The commonest cause of kernicterus is erythroblastosis fetalis when excessive amounts of bilirubin are generated from breakdown of incompatible red blood cells in the case of a Rhesus positive baby in a Rhesus negative mother. This tends to be more frequent and more severe in prematurely born infants. However,

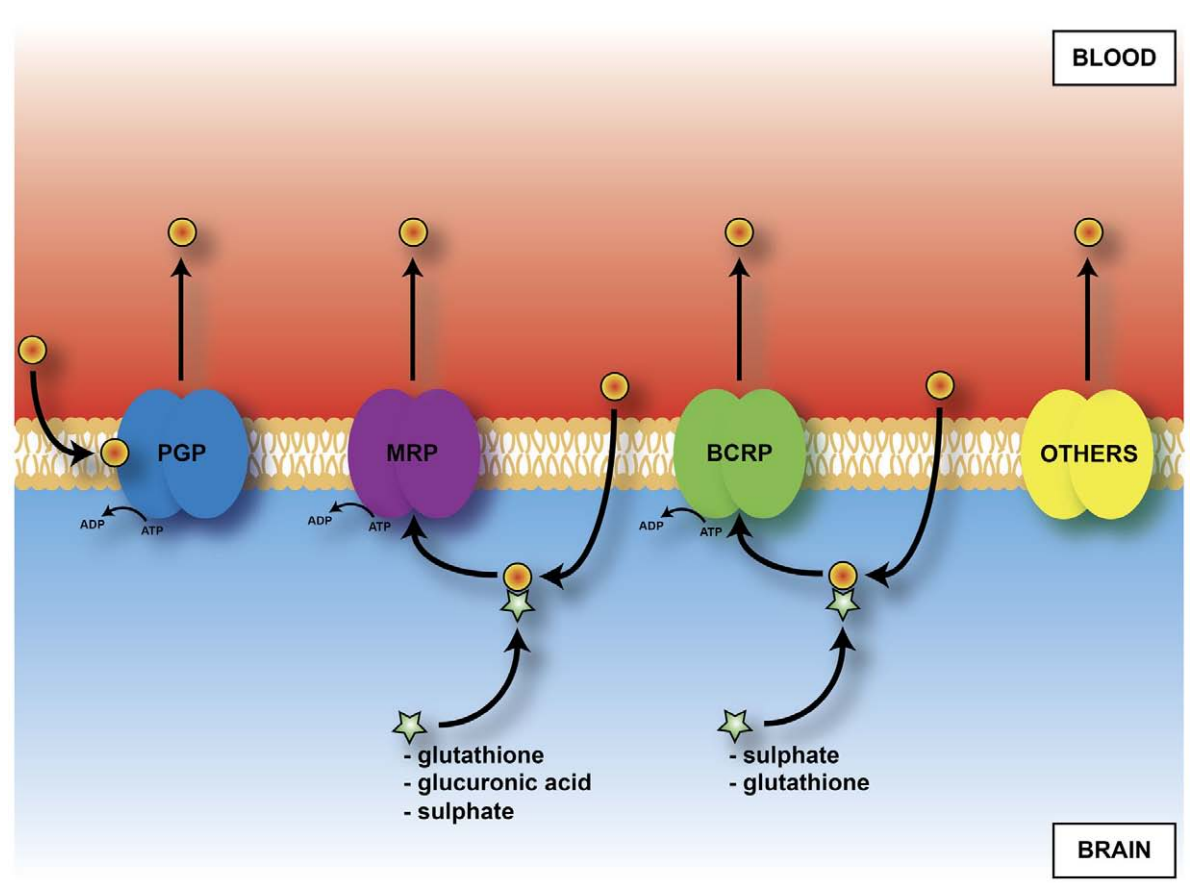

FIGURE 7 | Diagram of main outward transporters in cerebral endothelial cells. Some, e.g., PGP, (P-glycoprotein) prevent entry. For others, e.g., MRP (multidrug resistance-associated protein), ligand (drug or toxin) combines with glutathione, glucuronic acid or sulfate in cells before efflux. 
there seems to be no clear-cut level of unconjugated bilirubin at which all babies will, or will not suffer from kernicterus and it has become increasingly clear that factors in addition to bilirubin binding to albumin are involved (Wennberg, 2000; Wennberg et al., 2006). Although immaturity of the blood-brain barrier in the sense of "leakiness" is not one of these, there are other brain barrier mechanisms that may contribute. Thus bilirubin is a substrate for the efflux transporter P-glycoprotein and possibly also other efflux transporters (Yokooji et al., 2010; Gazzin et al., 2011). Although P-glycoprotein is expressed in fetal brain endothelial cells early in gestation its levels are higher in the adult (Schumacher and Møllgård, 1997; Virgintino et al., 2008; Ek et al., 2010) so it is possible that the efflux capacity of Pglycoprotein is exceeded in the presence of high levels of unconjugated bilirubin. Other efflux transporters are present in fetal cerebral endothelial cells and choroid plexus that are expressed at higher levels in the fetus than in the adult (Ek et al., 2010, see previous section) but it is not clear if bilirubin is also a substrate for these transporters. Another factor is that as described above there is a developmentally regulated transport of albumin from blood to CSF across the epithelial cells of the choroid plexus in the fetal brain. This albumin would presumably carry any bound unconjugated bilirubin into the CSF and thence the

\section{REFERENCES}

Abbott, N. J., Patabendige, A. A., Dolman, D. E., Yusof, S. R., and Begley, D. J. (2010). Structure and function of the blood-brain barrier. Neurobiol. Dis. 37, 13-25.

Abbott, N. J., Rönnbäck, L., and Hanssonet, E. (2006). Astrocyteendothelial interactions at the blood-brain barrier. Nat. Rev. Neurosci. 7, 41-53.

Adinolfi, M. (1985). The development of the human blood-CSF-brain barrier. Dev. Med. Child Neurol. 27, 532-537.

Adinolfi, M., Beck, S. E., Haddad, S. A., and Seller, M. J. (1976). Permeability of the blood-cerebrospinal fluid barrier to plasma proteins during foetal and perinatal life. Nature 259, 140-141.

Adinolf, M., and Haddad, S. A. (1977). Levels of plasma proteins in human and rat fetal CSF and the development of the bloodCSF barrier. Neuropadiatrie 8, 345-353.

Al-Sarraf, H. (2002). Transport of 14C-gamma-aminobutyric acid into brain, cerebrospinal fluid and choroid plexus in neonatal and adult rats. Brain Res. Dev. Brain Res. 139, 121-129.

Al-Sarraf, H., Preston, J. E., and Segal, M. B. (1997). Changes in the kinetics of the acidic amino acid brain and CSF uptake during development in the rat. Brain Res. Dev. Brain Res. $102,127-134$.
Amtorp, O., and Sørensen, S. C. (1974). The ontogenetic development of concentration differences or protein and ions between plasma and cerebrospinal fluid in rabbits and rats. J. Physiol. 243, 387-400.

Armulik, A., Genové, G., Mäe, M., Nisancioglu, M. H., Wallgard, E., Niaudet, C., He, L., Norlin, J., Lindblom, P., Strittmatter, K., Johansson, B. R., and Betsholtz, C. (2010). Pericytes regulate the blood-brain barrier. Nature 468, 557-561.

Armulik, A., Genové, G., and Betsholtz, C. (2011). Pericytes: developmental, physiological, and pathological perspectives, problems, and promises. Dev. Cell 21, 193-215.

Bakay, L. (1953). Studies on blood-brain barrier with radioactive phosphorus. III. Embryonic development of the barrier. AMA Arch. Neurol. Psychiatry 70, 30-39. blood-brain barrier," in The BloodBrain Barrier, with Special Regard to the use of Radioactive Isotopes, Chap. 7, ed. L. Bakay (Springfield, IL: Thomas), 77-149.

Bakay, L. (1968). Changes in barrier effect in pathological states. Prog. Brain Res. 29, 315-339.

Balslev, Y., Saunders, N. R., and Møllgård, K. (1997a). Ontogenetic development of diffusional restriction to protein at the pial surface of the rat brain; an electron microscopical study. J. Neurocytol. 26, 133-148.
Bakay, L. (1956). "Development of the

brain unless removed by the efflux transporters in the choroid plexuses.

\section{CONCLUSION}

Recent evidence confirms that the brain develops within a wellcontrolled internal environment. Tight junctions and many of the transport mechanisms (both inward and outward) are already present in the cellular interfaces between the blood, brain, and CSF, very early in development. Some properties of these barrier mechanisms and their susceptibility to disruption may lead to brain damage and later neurological disorders. We hope that this review will contribute to laying to rest the myth of the "leaky" or "immature" blood-brain barrier and focus attention on the need to understand better the level of function of barrier mechanisms that protect the brain from exposure to drugs and toxins, so that clinical advice will be based on the reality of evidence rather than teleological belief.

\section{ACKNOWLEDGMENTS}

The authors are supported by the National Health and Medical Research Council (Australia) - Grant No. 567205 and the EU Seventh Frame work Program (FP7) Neurobid consortium Agreement No. HEALTH-F2-2009-241778.

Balslev, Y., Dziegielewska, K. M., Møllgård, K., and Saunders, N. R. (1997b). Intercellular barriers to and transcellular transfer of albumin in the fetal sheep brain. Anat. Embryol. 195, 229-236.

Baños, G., Daniel, P. M., and Pratt, O. E. (1978). The effect of age upon the entry of some amino acids into the brain, and their incorporation into cerebral protein. Dev. Med. Child Neurol. 20, 335-346.

Bär, T. H., and Wolff, J. R. (1972). The formation of capillary basement membranes during internal vascularization of the rat's cerebral cortex. Z. Zellforsch. Mikrosk. Anat. 133, 231-248.

Barber, A. J., and Lieth, E. (1997). Agrin accumulates in the brain microvascular basal lamina during development of the blood-brain barrier. Dev. Dyn. 208, 62-74.

Barcroft, J. (1938). The Brain and its Environment. 1. The Activity of the Brain in Mid-Foetal Life. New Haven: Yale University Press.

Barrett, K. E., Barman, S. M., Boitano, S., and Brooks, H. (2010). Ganong's Review of Medical Physiology, 23rd Edn. New York: McGraw Hill, 530.

Bass, N. H., and Lundborg, P. (1973). Postnatal development of bulk flow in the cerebrospinal fluid system of the albino rat: clearance of carboxyl-(14C)inulin after intrathecal infusion. Brain Res. 52, 323-332.
Bass, T., Singer, G., Slusser, J., and Liuzzi, F. J. (1992). Radial glial interaction with cerebral germinal matrix capillaries in the fetal baboon. Exp. Neurol. 118, 126-132.

Bauer, H., Sonnleitner, U., Lametschwandtner, A., Steiner, M., Adam, H., and Bauer, H. C. (1995). Ontogenic expression of the erythroidtype glucose transporter (Glut 1) in the telencephalon of the mouse: correlation to the tightening of the blood-brain barrier. Brain Res. Dev. Brain Res. 86, 317-325.

Bauer, H. C., Bauer, H., Lametschwandtner, A., Amberger, A., Ruiz, P., and Steiner, M. (1993). Neovascularization and the appearance of morphological characteristics of the blood-brain barrier in the embryonic mouse central nervous system. Brain Res. Dev. Brain Res. 75, 269-278.

Behnsen, G. (1927). Über die farbstoffspeicherung im zentralnervensystem der weissen maus in verschiedenen alterzusstanden. Z. Zellforsch. Mikrosk. Anat. 4, 515-572.

Biedl, A., and Kraus, R. (1898). Übereiner bisher unbekannte toxische Wirkung der Gallensauren auf das Zentralnervensystyem. Zentralblatt. Inn. Med. 19, 1185-1200.

Bito, L. Z., and Myers, R. E. (1970). The ontogenesis of haematoencephalic cation transport processes in the rhesus monkey. J. Physiol. 208, $153-170$. 
Blasig, I. E., Winkler, L., Lassowski, B., Mueller, S. L., Zuleger, N., Krause, E., Krause, G., Gast, K., Kolbe, M., and Piontek, J. (2006). On the selfassociation potential of transmembrane tight junction proteins. Cell. Mol. Life Sci. 63, 505-514.

Bradbury, M. W., Crowder, J., Desai, S., Reynolds, J. M., Reynolds, M., and Saunders, N. R. (1972). Electrolytes and water in the brain and cerebrospinal fluid of the foetal sheep and guinea-pig. J. Physiol. (Lond.) 227, 591-610.

Braun, L. D., Cornford, E. M., and Oldendorf, W. H. (1980). Newborn rabbit blood-brain barrier is selectively permeable and differs substantially from the adult. J. Neurochem. 34, 147-152.

Brightman, M. W., and Reese, T. S. (1969). Junctions between intimately apposed cell membranes in the vertebrate brain. J. Cell Biol. 40, 48-77.

Caley, D. W., and Maxwell, D. S. (1970). Development of the blood vessels and extracellular spaces during postnatal maturation of rat cerebral cortex. J. Comp. Neurol. 138, 31-47.

Canfield, A. E., Schor, A. M., Loskutoff, D. J., Schor, S. L., and Grant, M. E. (1989). Plasminogen activator inhibitor-type I is a major biosynthetic product of retinal microvascular endothelial cells and pericytes in culture. Biochem. J. 259, 529-535.

Chowanadisai, W., Kelleher, S. L., and Lönnerdal, B. (2005). Zinc deficiency is associated with increased brain zinc import and LIV-1 expression and decreased ZnT-1 expression in neonatal rats. J. Nutr. 135, 1002-1007.

Cohen-Kashi Malina, K., Cooper, I., and Teichberg, V. I. (2009). Closing the gap between the in-vivo and in-vitro blood-brain barrier tightness. Brain Res. 1284, 12-21.

Colegio, O. R., Van Itallie, C., Rahner, C., and Anderson, J. M. (2003). Claudin extracellular domains determine paracellular charge selectivity and resistance but not tight junction fibril architecture. Am. J. Physiol. Cell Physiol. 284, C1346-C1354.

Cornford, E. M., Braun, L. D., and Oldendorf, W. H. (1982). Developmental modulations of blood-brain barrier permeability as an indicator of changing nutritional requirements in the brain. Pediatr. Res.16, 324-328.

Costa, L. G., Aschner, M., Vitalone, A., Syversen, T., and Soldin, O. P. (2004). Developmental neuropathology of environmental agents. Annu.
Rev. Pharmacol. Toxicol. 44, 87-110.

Damkier, H. H., Brown, P. D., and Praetorius, J. (2010). Epithelial pathways in choroid plexus electrolyte transport. Physiology 25, 239-249.

Dammann, O., and Leviton, A. (1997). Maternal intrauterine infection, cytokines and brain damage in the preterm newborn. Pediatr. Res. 42, 1-8.

Daneman, R., Agalliu, D., Zhou, L., Kuhnert, F., Kuo, C. J., and Barres, B. A. (2009). Wnt/beta-catenin signaling is required for CNS, but not nonCNS, angiogenesis. Proc. Natl. Acad. Sci. U.S.A. 106, 641-646.

Daneman, R., Zhou, L., Agalliu, D., Cahoy, J. D., Kaushal, A., and Barres, B. A. (2010a). The mouse blood-brain barrier transcriptome: a new resource for understanding the development and function of brain endothelial cells. PLoS ONE 5, e13741. doi:10.1371/journal.pone.0013741

Daneman, R., Zhou, L., Kebede, A. A., and Barres, B. A. (2010b). Pericytes are required for blood-brain barrier integrity during embryogenesis. Nature 468, 562-566.

Davson, H. (1967). Physiology of the Cerebrospinal Fluid. London: Churchill, 231-239.

Dehouck, M.-P., Méresse, S., Delorme, P., Fruchart, J.-C., and Cecchelli, R. (1990). An easier, reproducible, and mass-production method to study the blood-brain barrier in vitro. $J$. Neurochem. 54, 1798-1801.

del Zoppo, G. L., and Milner, R. (2006). Integrin-matrix interactions in the cerebral microvasculature. Arterioscler. Thromb. Vasc. Biol. 26, 1966-1975.

Dermietzel, R., Krause, D., Kremer, M., Wang, C., and Stevenson, B. (1992). Pattern of glucose transporter (Glut 1) expression in embryonic brains is related to maturation of bloodbrain barrier tightness. Dev. Dyn. 193, 152-163.

Donahue, S., and Pappas, G. D. (1961). The fine structure of capillaries in the cerebralcortex of the rat at various stages of development. Am. J. Anat. 108, 331-347.

Dziegielewska, K. M., Daikuhara, Y., Ohnishi, T., Waite, P. M. E., Ek, J., Habgood, M. D., Lane, M. A., Potter, A., and Saunders, N. R. (2000). Fetuin in the developing neocortex of the rat: distribution and origin. J. Comp. Neurol. 423, 373-388.

Dziegielewska, K. M., Evans, C. A. N., Malinowska, D. H., Møllgård, K., Reynolds, J. M., Reynolds, M. L., and Saunders, N. R. (1979). Studies of the development of brain barrier systems to lipid insoluble molecules in fetal sheep. J. Physiol. 292, 207-231.

Dziegielewska, K. M., Evans, C. A. N., Malinowska, D. H., Møllgård, K., Reynolds, M. L., and Saunders, N. R. (1980). Blood-cerebrospinal fluid transfer of plasma proteins during fetal development in the sheep. $J$. Physiol. 300, 457-465.

Dziegielewska, K. M., Habgood, M. D., Møllgård, K., Stagaard, M., and Saunders, N. R. (1991). Speciesspecific transfer of plasma albumin from blood into different cerebrospinal fluid compartments in the fetal sheep. J. Physiol. 439, 215-237.

Dziegielewska, K. M., and Saunders, N. R. (1988). "The development of the blood-brain barrier: proteins in fetal and neonatal CSF, their nature and origins," in Handbook of Human Growth and Developmental Biology. Vol. 1. Neural, Sensory, Motor and Integrative Development, eds E. Meisami and P. S. Timiras (Boca Raton: CRC Press), 169-191.

Ehrlich, P. (1885). Das sauerstoffbedurfnis des organismus. Eine farbenanalytische studie. Berlin: Hirschwald.

Ek, C. J., Dziegielewska, K. M., Habgood, M. D., and Saunders, N. R. (2012). Barriers in the developing brain and Neurotoxicology. Neurotoxicology. doi:10.1016/j.neuro.2011.12.009. [Epub ahead of print].

Ek, C. J., Habgood, M. D. Dziegielewska, K. M., and Saunders, N. R. (2003). Structural characteristics and barrier properties of the choroid plexuses in developing brain of the opossum (Monodelphis domestica). J. Comp. Neurol. 460, 451-464.

Ek, C. J., Habgood, M. D., Dziegielewska, K. M., and Saunders, N. R. (2006). Functional effectiveness of the blood-brain barrier to small water-soluble molecules in developing and adult opossum (Monodelphis domestica). J. Comp. Neurol. 496, 13-26.

Ek, C. J., Wong, A., Liddelow, S. A., Johansson, P. A., Dziegielewska, K. M., and Saunders, N. R. (2010). Efflux mechanisms at the developing brain barriers: ABC-transporters in the fetal and postnatal rat. Toxicol. Lett. 197, 51-59.

Ek, J., Habgood, M. D., Dziegielewska, K. M., and Saunders, N. R. (2001). Permeability of the blood-brain and blood-CSF barriers to small molecular weight lipid insoluble markers during postnatal development in the opossum, Monodelphis domestica. J. Physiol. 536, 841-853.

Fossan, G., Cavanagh, M. E., Evans, C. A. N., Malinowska, D. H., Møllgård, K., Reynolds, M. L., and Saunders, N. R. (1985). CSF-brain permeability in the immature sheep fetus: a CSFbrain barrier. Brain Res. Dev. Brain Res. 18, 113-124.

Frömter, E., and Diamond, J. (1972). Route of passive ion permeation in epithelia. Nat. New Biol. 235, 9-13.

Furuse, M., Furuse, K., Sasaki, H., and Tsukita, S. (2001). Conversion of Zonulae Occludentes from Tight to Leaky Strand Type by Introducing Claudin-2 into Madin-Darby Canine Kidney I Cells. J. Cell Biol. 153, 263-272.

Furuse, M., Itoh, M., Hirase, T., Nagafuchi, A., Yonemura, Y., Tsukita, S., and Tsukita, S. (1994). Direct association of occludin with ZO-1 and its possible involvement in the localization of occludin at tight junctions. $J$. Cell Biol. 127, 1617-1626.

Furuse, M., and Tsukita, S. (2006). Claudins in occluding junctions of humans and flies. Trends Cell Biol. 16, 181-188.

Gazzin, S., Berengeno, A. L., Strazielle, N., Fazzari, F., Raseni, A., Ostrow, J. D., Wennberg, R., Ghersi-Egea, J.-F., and Tiribelli, C. (2011). Modulation of Mrp1 (ABCcl) and Pgp (ABCb1) by bilirubin at the blood-CSF and blood-brain barriers in the Gunn rat. PLoS ONE 6, e16165. doi:10.1371/journal.pone.0016165

Goldmann, E. E. (1909). Die aussere und innere Sekretion des gesunden und kranken Organismus im Lichte der “vitalen Farbung." Beitr. Klin. Chir. 64, 192-265.

Gröntoft, O. (1954). Intracranial haemorrhage and blood-brain barrier problems in the newborn: a pathologico-anatomical and experimental investigation. Acta Pathol. Microbiol. Scand. Suppl. 100, 8-109.

Habgood, M. D., Knott, G. W., Dziegielewska, K. M., and Saunders, N. R. (1993). The nature of the blood-CSF barrier permeability decrease during postnatal brain development in the rat. J. Physiol. 468, 73-83.

Habgood, M. D., Sedgwick, J. E. C., Dziegielewska, K. M., and Saunders, N. R. (1992). A developmentally regulated blood-cerebrospinal fluid transfer mechanism for albumin in immature rats. J. Physiol. 456, 181-192. 
Hagenbuch, B. (2007). Cellular entry of thyroid hormones by organic anion transporting polypeptides. Best Pract. Res. Clin. Endocrinol. Metab. 21, 209-221.

Hartz, A. M. S., and Bauer, B. (2011). ABC transporters in the CNS - an inventory. Curr. Pharm. Biotechnol. 12, 656-673.

Haseloff, R. F., Blasig, I. E., Bauer, H. C., and Bauer, H. (2005). In search of the astrocytic factor(s) modulating blood-brain barrier functions in brain capillary endothelial cells in vitro. Cell. Mol. Neurobiol. 25, 25-39.

Himwich, W. A., Petersen, J. C., and Allen, M. L. (1957). Hematoencephalic exchange as a function of age. Neurology 7, 705-710.

Hirase, T., Staddon, J. M., Saitou, M., Ando-Akatsuka, Y., Itoh, M., Furuse, M., Fujimoto, K., Tsukita, S., and Rubin, L. L. (1997). Occludin as a possible determinant of tight junction permeability in endothelial cells. J. Cell. Sci. 110, 1603-1613.

Holash, J. A., Noden, D. M., and Stewart, P. A. (1993). Re-evaluating the role of astrocytes in blood-brain barrier induction. Dev. Dyn. 197, 14-25.

Itoh, M., Sasaki, H., Furuse, M., Ozaki, H., Kita, T., and Tsukita, S. (2001). Junctional adhesion molecule (JAM) binds to PAR-3: a possible mechanism for the recruitment of PAR-3 to tight junctions. J. Cell Biol. 154, 491-497.

Janzer, R. C., and Raff, M. C. (1987). Astrocytes induce blood-brain barrier properties in endothelial cells. Nature 325, 253-257.

Järup, L. (2003). Hazards of heavy metal contamination. Br. Med. Bull. 68, 167-182.

Johanson, C. E., and Woodbury, D. M. (1974). "Changers in CSF flow and extracellular space in the developing rat," in Drugs and the Developing Brain, eds A. Vernadakis and N. Weiner (New York: Plenum), 281-287.

Johansson, P. A., Burnstock, G., Dziegielewska, K. M., Guida, E., McIntyre, P., and Saunders, N. R. (2007). Expression and localization of P2 nucleotide receptor subtypes during development of the lateral ventricular choroid plexus of the rat. Eur. J. Neurosci. 26, 3319-3331.

Johansson, P. A., Dziegielewska, K. M., Ek, C. J., Habgood, M. D., Liddelow, S. A., Potter, A. M., Stolp, H. B., and Saunders, N. R. (2006). Blood-CSF barrier function in the rat embryo. Eur. J. Neurosci. 24, 65-76.
Johansson, P. A., Dziegielewska, K. M., Ek, C. J., Habgood, M. D., Møllgård, K., Potter, A., Schuliga, M., and Saunders, N. R. (2005). Aquaporin1 in the choroid plexuses of developing mammalian brain. Cell Tissue Res. 322, 353-364.

Johansson, P. A., Dziegielewska, K. M., Liddelow, S. A., and Saunders, N. R. (2008). The blood-CSF barrier explained: when development is not immaturity. Bioessays 30, 237-248.

Jones, H. C. (1980). Intercellular pores between the ependymal cells lining the roof of the 4 th cerebral ventricle in mammalian fetuses. Z. Kinderchir. 31, 309-316.

Jones, H. C., and Bucknall, R. M. (1988). Inherited prenatal hydrocephalus in the H-Tx rat: a morphological study. Neuropathol. Appl. Neurobiol. 14, 263-274.

Jones, H. C., and Sellars, R. A. (1982). The movement of fluid out of the cerebral ventricles in fetal and neonatal rats. Z. Kinderchir. 37, 130-133.

Kniesel, U., Risau, W., and Wolburg, H. (1996). Development of bloodbrain barrier tight junctions in the rat cortex. Brain Res. Dev. Brain Res. 96, 229-240.

Knott, G. W., Dziegielewska, K. M., Habgood, M. D., Li, Z. S., and Saunders, N. R. (1997). Albumin transfer across the choroid plexus of South American opossum (Monodelphis domestica). J. Physiol. 499, 179-194.

Kuttner, R., Sims, J. A., and Gordon, M. W. (1961). The uptake of a metabolically inert amino acid by brain and other organs. J. Neurochem. 6, 311-317.

Lajtha, A., and Toth, J. (1961). The brain barrier system-II. Uptake and transport of amino acids by the brain. $J$. Neurochem. 8, 216-225.

Lee, J. C. (1971). Evolution of the concept of the blood-brain barrier phenomenon. Prog. Neuropathol. 1, 84-145.

Lefauconnier, J.-M., and Trouvé, R. (1983). Developmental changes in the pattern of amino acid transport at the blood-brain barrier in rats. Brain Res. 283, 175-182.

Lewandowsky, M. (1900). Zur lehre der cerebrospinal flussigkeit. Z. Klin. Med. 40, 480-494.

Liddelow, S., Dziegielewska, K. M., Ek, C. J., Johansson, P. A., Potter, A., and Saunders, N. R. (2009). Cellular transfer of macromolecules across the developing choroid plexus of Monodelphis domestica. Eur. J. Neurosci. 29, 253-266.
Liddelow, S., Dziegielewska, K. M., Noor, N., Potter, A. M., and Saunders, N. R. (2011a). Modification of choroid plexus protein transfer from blood to cerebrospinal fluid in response to altered plasma protein composition during development. Eur. J. Neurosci. 33, 391-400.

Liddelow, S. A., Dziegielewska, K. M. Møllgård, K., Phoenix, T. N., Temple, S., VandeBerg, J. L., and Saunders, N. R. (2011b). Sparc/osteonectin, an endogenous mechanism for targeting albumin to the blood-CSF interface during brain development. Eur. J. Neurosci. 34, 1062-1073.

Liddelow, S. A., Temple, S., Møllgård, K., Gehwold, R., Wagner, A., Bauer, H., Bauer, H.-C., Phoenix, T. N., Dziegielewska, K. M., and Saunders, N. R. (2012). Molecular characterisation of transport mechanisms at the developing mouse blood-CSF interface: a transcriptome approach. PLOS ONE. (in press).

Liebner, S., Corada, M., Bangsow, T., Babbage, J., Taddei, A., Czupolla, C. J., Reis, M., Felici, A., Wolburg, H., Fruttiger, M., Taketo, M. M., von Melchner, H., Plate, K. H., Gerhardt, H., and Dejana, E. (2008). Wnt/beta-catenin signaling controls development of the blood-brain barrier. J. Cell Biol.183, 409-417.

Møllgård, K., Balslev, Y., Lauritzen, B. and Saunders, N. R. (1987). Cell junctions and membrane specializations in the ventricular zone (germinal matrix) of the developing sheep brain: a CSF-brain barrier. J. Neurocytol. 16, 433-444.

Møllgård, K., Lauritzen, B., and Saunders, N. R. (1979). Double replica technique applied to choroid plexus from early foetal sheep: completeness and complexity of tight junctions. J. Neurocytol. 8, 139-149.

Møllgård, K., Malinowska, D. H., and Saunders, N. R. (1976). Lack of correlation between tight junction morphology and permeability properties in developing choroid plexus. Nature 264, 293-294.

Møllgård, K., and Saunders, N. R. (1975). Complex tight junctions of epithelial and of endothelial cells in early foetal brain. J. Neurocytol. 4, 453-468.

Morgan, E. H., and Moos, T. (2002). Mechanism and developmental changes in iron transport across the blood-brain barrier. Dev. Neurosci. 24. 106-113.

Neuwelt, E. A. (2004). Mechanisms of disease: the blood-brain barrier. Neurosurgery 54, 131-140.
Nitta, T., Hata, M., Gotoh, S., Seo, Y., Sasaki, H., Hashimoto, N., Furuse, M., and Tsukita, S. (2003). Sizeselective loosening of the bloodbrain barrier in claudin-5-deficient mice. J. Cell Biol. 161, 653-660.

Oldendorf, W. M. (1971). Brain uptake of radiolabeled amino acids, amines, and hexoses after arterial injection. Am. J. Physiol. 221, 1629-1639.

Olney, J. W., and Ho, O. L. (1970). Brain damage in infant mice following oral intake of glutamate, aspartate or cysteine. Nature 227, 609-611.

Palis, J., Malik, J., Mcgrath, K. E., and Kingsley, P. D. (2010). Primitive erythropoiesis in the mammalian embryo. Int. J. Dev. Biol. 54, 1011-1018.

Pardridge, W. M., and Mietus, L. J. (1982). Kinetics of neutral amino acid transport through the bloodbrain barrier of the newborn rabbit. J. Neurochem. 38, 955-962.

Penta, P. (1932). Sulla colorazione vitale del sistema nervosa negli centrale animali neonati. Riv. Neurol. 5, 62-80.

Porterfield, S. P., and Hendrich, C. E. (1992). Tissue iodothyronine levels in fetuses of control and hypothyroid rats at 13 and 16 days gestation. Endocrinology 131, 195-200.

Purpura, D. P., and Carmichael, M. W. (1960). Characteristics of blood-brain barrier to gammaaminobutyric acid in neonatal cat. Science 131, 410-412.

Ramey, B. A., and Birge, W. J. (1979). Development of cerebrospinal fluid and the blood-cerebrospinal fluid barrier in rabbits. Dev. Biol. 68, 292-298.

Risau, W., Hallmann, R., and Albrecht, U. (1986). Differentiationdependent expression of proteins in brain endothelium during development of the blood-brain barrier. Dev. Biol. 117, 537-545.

Risau, W., and Wolburg, H. (1990). Development of the blood-brain barrier. Trends Neurosci. 13, 174-178.

Roberts, R. B., Flexner, J. B., and Flexner, L. B. (1959). Biochemical and physiological differentiation during morphogenesis. XXIII. Further observations relating to the synthesis of amino acids and proteins by the cerebral cortex and liver of the mouse. J. Neurochem. 4, 78-90.

Roediger, M., Miosge, N., and Gersdorff, N. (2010). Tissue distribution of the laminin $\beta 1$ and $\beta 2$ chain during embryonic and fetal human development. J. Mol. Histol. 41, 177-184. 
Rubin, L. L., Hall, D. E., Porter, S., Barbu, K., Cannon, C., Horner, H. C., Janatpour, M., Liaw, C. W., Manning, K., Morales, J., Tanner, L. I., Tomaselli, K. J., and Bard, F. (1991). A cell culture model of the bloodbrain barrier. J. Cell Biol. 115, 17251735.

Rudloff, S., Messerschmidt, D., and Kemler, R. (2011). "Wnt signaling in development," in Intercellular Signaling in Development and Disease: Cell Signaling Collection, Chap. 21, eds E. A. Dennis and R. A. Bradshaw (San Diego: Academic Press), 215-220.

Sadowska, G. B., Malaeb, S. N., and Stonestreet, B. S. (2009). Maternal glucocorticoid exposure alters tight junction protein expression in the brain of fetal sheep. Am. J. Physiol. Heart Circ. Physiol. 298, H179H188.

Saitou, M., Fujimoto, K., Do, Y., Itoh, M., Fujimoto, T., Furuse, M., Takano, H., Noda, T., and Tsukita, S. (1998). Occludin-deficient embryonic stem cells can differentiate into polarized epithelial cells bearing tight junctions. J. Cell Biol. 141, 397-408.

Saunders, N. R. (1992). "Ontogenetic development of brain barrier mechanisms," in Physiology and Pharmacology of the Blood Brain-Barrier. Vol. 103. Handbook of Experimental Pharmacology, ed. M. W. B. Bradbury (Berlin: Springer-Verlag), 327-369.

Saunders, N. R., Ek, C. J., Habgood, M. D., and Dziegielewska, K. M. (2008). Barriers in the brain: a renaissance? Trends Neurosci. 31, 279-236.

Saunders, N. R., and Habgood, M. D. (2011). Understanding barrier mechanisms in the developing brain to aid therapy for the dysfunctional brain. Future Neurol. 6, 187-199.

Saunders, N. R., Habgood, M. D., and Dziegielewska, K. M. (1999). Barrier mechanisms in the brain II immature brain. Clin. Exp. Pharmacol. Physiol. 26, 85-91.

Saunders, N. R., Habgood, M. D., and Dziegielewska, K. M. (2010). "Neurotoxicology of barriers in the developing brain," in Developmental Neurotoxicology, Chap. 3, eds J. Harry, $\mathrm{H}$. Tilson (New York: Informa Health Care), 50-78.

Schrieber, G., Aldred, A. R., Jaworowski, A., Nilsson, C., Achen, M. G., and Segal, M. B. (1990). Thyroxine transport from blood to brain via transthyretin synthesis in choroid plexus. Am. J. Physiol. 258, R338R345.
Schumacher, U., and Møllgård, K. (1997). The multidrug-resistance Pglycoprotein (Pgp, MDR1) is an early marker of blood-brain barrier development in the microvessels of the developing human brain. Histochem. Cell Biol. 108, 179-182.

Seta, K., Sershen, H., and Lajtha, A. (1972). Cerebral amino acid uptake in vivo in newborn mice. Brain Res. 47, 415-425.

Sonoda, N., Furuse, M., Sasaki, H., Yonemura, S., Katahira, J., Horiguchim, Y., and Tsukita, S. (1999). Clostridium perfringens enterotoxin fragment removes specific claudins from tight junction strands: evidence for direct involvement of claudins in tight junction barrier. J. Cell Biol. 147, 195-204.

Stenman, J. M., Rajagopal, J., Carroll, T. J., Ishibashi, M., McMahon, J., and McMahon, A. P. (2008). Canonical Wnt signaling regulates organspecific assembly and differentiation of CNS vasculature. Science 322, 1247-1250.

Stern, L., and Peyrot, R. (1927). Le fonctionnement de la barrière hématoencéphalique aux diverse stades de développement chez les diverses especes animals. C. R. Soc. Biol. (Paris) 96, 1124-1126.

Stern, L., and Rapoport, J. L. (1928). Les rapports entre l'augmentation de la perméabilité de la barrière hématoencéphalique et les altérations de son substratum morphologique. $C$. R. Soc. Biol. (Paris) 98, 15151517.

Stern, L., Rapoport, J. L., and Lokschina, E.-S. (1929). Le fonctionnement de la barrière hémato-encéphalique chez les nouveau nés. C. R. Soc. Biol. (Paris) 100, 231-223.

Stewart, P. A., and Hayakawa, E. M. (1987). Interendothelial junctional changes underlie the developmental "tightening" of the blood-brain barrier. Brain Res. Dev. Brain Res. 32, 271-281.

Stewart, P. A., and Hayakawa, E. M. (1994). Early ultrastructural changes in blood-brain barrier vessels of the rat embryo. Brain Res. Dev. Brain Res. 78, 25-34.

Stewart, P. A., and Wiley, M. J. (1981). Developing nervous tissue induces formation of blood-brain barrier characteristics in invading endothelial cells: a study using quail-chick transplantation chimeras. Dev. Biol. 84, 183-192.

Stolp, H. B., and Dziegielewska, K. M. (2009). Review: role of developmental inflammation and blood-brain barrier dysfunction in neurodevelopmental and neurodegenerative diseases. Neuropathol. Appl. Neurobiol. 35, 132-146.

Stolp, H. B., Dziegielewska, K. M., Ek, C. J., Habgood, M. D., Lane, M. A., Potter, A. M., and Saunders, N. R. (2005a). Breakdown of the bloodbrain barrier to proteins in white matter of the developing brain following systemic inflammation. Cell Tissue Res. 320, 369-378.

Stolp, H. B., Dziegielewska, K. M., Ek, C. J., Potter, A. M., and Saunders, N. R. (2005b). Long-term changes in blood-brain barrier permeability and white matter following prolonged systemic inflammation in early development in the rat. Eur. J. Neurosci. 22, 2805-2816.

Stolp, H. B., Dziegielewska, K. M., Saunders, N. R., Anthony, D. C., and Molnár, Z. (2011). Reduced ventricular proliferation in the foetal cortex following maternal inflammation in mouse. Brain 134, 3236-3248.

Stratman, A. N., and Davis, G. E. (2011). Endothelial cell-pericyte interactions stimulate basement membrane matrix assembly: influence on vascular tube remodeling, maturation, and stabilization. Microsc Microanal. 14, 1-13.

Tao-Cheng, J. H., Nagy, Z., and Brightman, M. W. (1987). Tight junctions of brain endothelium in vitro are enhanced by astroglia. J. Neurosci. 7, 3293-3299.

Tauc, M., Vignon, X., and Bouchaud, C. (1984). Evidence for the effectiveness of the blood-CSF barrier in the fetal rat choroid plexus. A freezefracture and peroxidase diffusion study. Tissue Cell 16, 65-74.

Urayama, A., Grubb, J. H., Sly, W. S., and Banks, W. A. (2008). Mannose 6phosphate receptor-mediated transport of sulfamidase across the bloodbrain barrier in the newborn mouse. Mol. Ther. 16, 1261-1266.

Vannucci, S. J. (1994). Developmental expression of GLUT1 and GLUT3 glucose transporters in rat brain. $J$. Neurochem. 62, 240-246.

Vannucci, S. J., Seaman, L. B., Brucklacher, R. M., and Vannucci, R. C. (1994). Glucose transport in developing rat brain: glucose transporter proteins, rate constants and cerebral glucose utilization. Mol. Cell. Biochem.140, 177-184.

Viña, J. R., DeJoseph, M. R., Hawkins, P. A., and Hawkins, R. A. (1997). Penetration of glutamate into brain of 7-day-old rats. Metab. Brain Dis. 12, 219-227.

Virgintino, D., Errede, M., Girolamo, F., Capobianco, C., Robertson,
D., Vimercati, A., Serio, G., Di Benedetto, A., Yonekawa, Y., Frei, K., and Roncali, L. (2008). Fetal blood-brain barrier P-glycoprotein contributes to brain protection during human development. J. Neuropathol. Exp. Neurol. 67, 50-61.

Virgintino, D., Errede, M., Robertson, D., Capobianco, C., Girolamo, F., Vimercati, A., Bertossi, M., and Roncali, L. (2004). Immunolocalization of tight junction proteins in the adult and developing human brain. Histochem. Cell Biol. 122, 51-59.

Wakai, S., and Hirokawa, N. (1978a). Development of the blood-brain barrier to horseradish peroxidase in the chick embryo. Cell Tissue Res.195, 195-203.

Wakai, S., and Hirokawa, N. (1978b). Development of bloodcerebrospinal fluid barrier to horseradish peroxidase in the avian choroidal epithelium. Cell Tissue Res. 214, 271-278.

Watson, R. E., Desesso, J. M., Hurtt, M. E., and Cappon, G. D. (2006). Postnatal growth and morphological development of the brain: a species comparison. Birth Defects Res. B Dev. Reprod. Toxicol. 77, 471-484.

Weed, L. H. (1917). The development of the cerebrospinal fluid spaces in pig and in man. Contrib. Embryol. 5, 41-52.

Wennberg, R. P. (2000). The blood-brain barrier and bilirubin encephalopathy. Cell. Mol. Neurobiol. 20, 97-109.

Wennberg, R. P., Ahlfors, C. E., Bhutani, V. K., Johnson, L. H., and Shapiro, S. M. (2006). Toward understanding kernicterus: a challenge to improve the management of jaundiced newborns. Pediatrics 117, 474-485.

Wislocki, G. B. (1920). Experimental studies on fetal absorption. I. The vitality stained fetus. Contrib. Embryol. 11, 45-60.

Wolburg, H., Wolburg-Buchholz, K., Liebner, S., and Engelhardt, B. (2001). Claudin-1, claudin-2 and claudin-11 are present in tight junctions of choroid plexus epithelium of the mouse. Neurosci. Lett. 307, 77-80.

Xie, J., Farage, E., Sugimoto, M., and Anand-Apte, B. (2010). A novel transgenic zebrafish model for blood-brain and blood-retinal barrier development. BMC Dev. Biol. 10, 76. doi: 10.1186/1471-213X$10-76$

Xu, J., and Ling, E.-A. (1994). Studies of the ultrastructure and permeability of the blood-brain barrier in the 
developing corpus callosum in postnatal rat brain using electron dense tracers. J. Anat. 184, 227-237.

Yokooji, T., Mori, N., and Murakami, T. (2010). Modulated function of tissue efflux transporters under hyperbilirubinemia in rats. Eur. J. Pharmacol. 636, 166-172.

Yoon, B. H., Romero, R., Park, J. S., Kim, C. J., Kim, S. H., Choi, J. H., and
Han, T. R. (2000). Fetal exposure to an intra-amniotic inflammation and the development of cerebral palsy at the age of 3 years. Am. J. Obstet. Gynecol. 182, 675-81.

Conflict of Interest Statement: The authors declare that the research was conducted in the absence of any commercial or financial relationships that could be construed as a potential conflict of interest.

Received: 24 January 2012; accepted: 29 February 2012; published online: 29 March 2012.

Citation: Saunders NR, Liddelow SA and Dziegielewska KM (2012) Barrier mechanisms in the developing brain. Front. Pharmacol. 3:46. doi: 10.3389/fphar.2012.00046
This article was submitted to Frontiers in Neuropharmacology, a specialty of Frontiers in Pharmacology.

Copyright (c) 2012 Saunders, Liddelow and Dziegielewska. This is an open-access article distributed under the terms of the Creative Commons Attribution Non Commercial License, which permits noncommercial use, distribution, and reproduction in other forums, provided the original authors and source are credited. 